\title{
El refugio en altura andalusí de Vilella (Almiserat, Valencia), un ejemplo de arquitectura defensiva rural en el ámbito centro-meridional valenciano (ca. 1150-1250)
}

\author{
The andalusí refuge of Vilella (Almiserat, Valencia), an example of rural \\ defensive architecture in the centre-southern Valencian area (ca. 1150-1250)
}

\author{
Miquel Sánchez i Signes \\ Arqueólogo \\ e-mail: miquelsignes@gmail.es
}

\begin{abstract}
RESUMEN
Presentamos en este trabajo los resultados del estudio realizado sobre el pequeño refugio rural de Vilella (Almiserat, Valencia), construido mediante la técnica del tapial durante los últimos momentos de dominación islámica en el Sharq al-Andalus. Se analizan la planta y las defensas del recinto (sistema de ingreso y torre oeste) y, sobre todo, los distintos tipos de fábrica de tapia y las improntas constructivas asociadas a esta técnica. También se analizan otras técnicas de construcción documentadas.
\end{abstract}

Palabras clave: Comunidad valenciana; islámico; tapia; mampostería; improntas de construcción.

\begin{abstract}
The results of the study of the small rural refuge of Vilella (Almiserat, Valencia), built in rammed earth technique in the last period of the Islamic domination in the Sharq al-Andalus, are here exposed. This work analyses the shape and the defences of the enclosure (access system and western tower) and, above all, the different types of rammed earth fabric and the building traces associated to it. It analyses as well other recorded building techniques.
\end{abstract}

Keywords: Valencian region; Islamic; tapia (rammed earth wall); masonry; building traces.

Recibido: 28/09/2012. Aceptado: 27/03/2013.

Cómo citar este artículo / Citation

Miquel Sánchez i Signes 2013: “El refugio en altura andalusí de Vilella (Almiserat, Valencia), un ejemplo de arquitectura defensiva rural en el ámbito centro-meridional valenciano (ca. 1150-1250)", Arqueología de la Arquitectura, 10: e005. doi: http://dx.doi.org/10.3989/arq. arqt. 2013.004

\section{Copyright}

(c) 2013 CSIC. Este es un artículo de acceso abierto distribuido bajo los términos de la licencia Creative Commons Attribution-Non Commercial (by-nc) Spain 3.0.

\section{I NTRODUCCIÓN Y CONTEXTO}

A lo largo del presente trabajo pretendemos abordar la revisión de un edificio defensivo concreto de época andalusí, localizado en el ámbito rural valenciano: se trata del refugio de Vilella (Almiserat, Valencia), ya publicado hace tres décadas por los investigadores franceses Pierre Guichard y André Bazzana (Bazzana 1983a, 1983b; Bazzana y Guichard, 1980; Bazzana, Guichard y Créssier, 1988). Este edificio se encuadra en la categoría de las construcciones con carácter defensivo en altura situadas en la zona meridional del antiguo reino de Valencia (ca. s. XIII), conocida en la documentación como Montanea Valencie. Actualmente, dicha zona ocupa un área esencialmente montañosa comprendida por seis comarcas entre el sur de la provincia de Valencia y el norte de la provincia de Alicante: Safor, Marina Alta, Marina Baja, Condado de Cocentaina, Hoya de Alcoy y Valle de Albaida (figura 1). Creemos necesario actualizar el 
estado de la cuestión sobre Vilella y, además, proceder a ampliar la información que se tiene de esta construcción mediante el estudio de los aparejos, técnicas constructivas y materiales empleados.

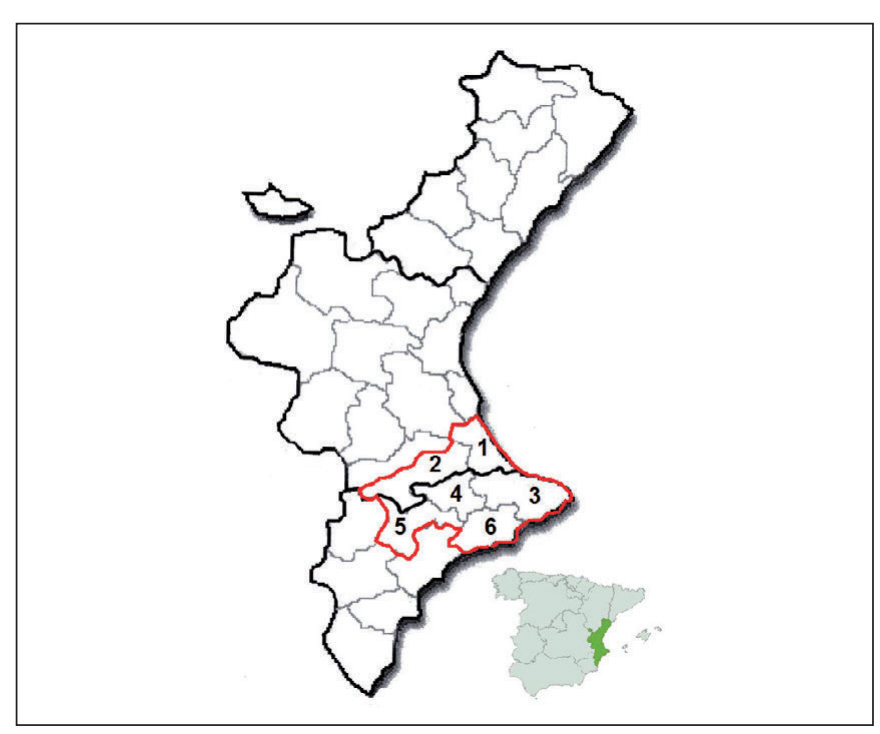

Figura 1: Plano de situación de las comarcas valencianas y alicantinas incluidas en nuestra área de interés (1. La Safor; 2. Valle de Albaida; 3. Marina Alta; 4. Condado de Cocentaina; 5. Hoya de Alcoy; 6. Marina Baja). (Fuente: TerraSit)

Los edificios de carácter defensivo, en su práctica totalidad de origen islámico, abundan en el área geográfica señalada. Se asientan sobre lomas, o montañas de mediana altura, y presentan una morfología muy variada. La historiografía lleva al menos tres décadas tratando de establecer una cronotipología válida dependiendo de la forma y función de estas construcciones (Azuar, 1981; Torró y Segura, 1991; Torró, 1998; Bazzana, 2002), y también de sus materiales y técnicas (López Elum, 2002), sin el éxito esperado, al menos en cuanto a una concepción global, a causa de su marcado localismo.

Las técnicas de ejecución de cada una de las construcciones ofrecen una amplia variedad formal, a pesar de que se basan, en la mayor parte, en el tapial y la mampostería. La arquitectura rural se encontraba condicionada por la escasa especialización de los oficios y la lejanía de los principales centros urbanos, de modo que se veía obligada a explotar los recursos de su entorno inmediato (Navarro y Jiménez, 2011: 86); en nuestro caso, el único centro urbano importante es Denia, situado en la costa y no siempre cercano a todas las aljamas del macizo montañoso al que hemos aludido. De este modo, en vísperas de la conquista cristiana, serían los pequeños poderes de las múltiples aljamas quienes organizasen y defendiesen el territorio, de forma que la cuestión tiende a complicarse aún más.

El período objeto de estudio se centra alrededor de las últimas décadas de poder almohade, entre la segunda mitad del siglo XII y el final del dominio mardanisí (1172) por una parte, y la descomposición política que sigue al inicio de la conquista cristiana del Sharq al-Andalus o levante peninsular, entre los años 1228 y 1233/1245 (Guichard, 2001; Torró, 2006), por otra. Responden a esta cronología, sobre todo, las torres defensivas de las alquerías islámicas y los refugios en altura: estos últimos se reforman ahora, aunque en otros casos se levantan ex novo para proteger a la población de las cabalgadas de los cristianos durante los momentos previos y coetáneos al avance de la conquista ${ }^{1}$. Como límite temporal hemos establecido la década de 1250, cuando finaliza la segunda revuelta de los musulmanes valencianos (1248-1258), la cual se extendió a lo largo del área de la Montanea Valencie. El hecho de plantear este límite para un edificio defensivo islámico se debe a que muchos puntos de protección y/o fortificados sufrieron en esos momentos cambios sustanciales que deben ser tenidos en cuenta: procesos de abandono y reocupación puntual, reformas de adaptación a la nueva sociedad cristiana y, también, casos de destrucción deliberada para evitar que los emplazamientos cayeran en manos de los musulmanes rebeldes.

\section{LOCALI ZACI ÓN GEOGRÁFICA DE VI LELLA}

El refugio andalusí de Vilella (734010, 4312533, huso 30S) se encuentra situado en el término municipal de Almiserat, a unos dos $\mathrm{km}$ al NNO de este núcleo urbano de poco más de trescientos habitantes. Pertenece a la comarca valenciana de la Safor y se halla a poca distancia del límite con la comarca del Valle de Albaida (figura 2), también en la provincia de Valencia, lo cual ha provocado algunas confusiones en cuanto a su localización geográfica, sobre todo porque en esta última existe un despoblado con el mismo nombre que el del refugio (Bazzana y Guichard, 1980).

\footnotetext{
${ }^{1}$ La mayor parte de las fortificaciones desde mediados del siglo XII a principios del siglo XIII responde a las necesidades de protección de las comunidades andalusíes, lo cual implicó en el caso valenciano la creación de una densa red de castillos, torres y recintos defensivos (Azuar, 1989; S/a., 1996; Centre d'Estudis Contestans, 1996, 2009) contra las incursiones de los cristianos (Azuar, 1981, 1989; Guichard, 2001), un impulso que tras la descomposición del poder almohade a partir del año 1228 quedó asociado en los casos en los que fue posible a la iniciativa de las propias aljamas, las cuales previeron su propia defensa (Guichard, 1982; Bazzana y Guichard, 1983; Bazzana, Guichard y Créssier, 1988).
} 


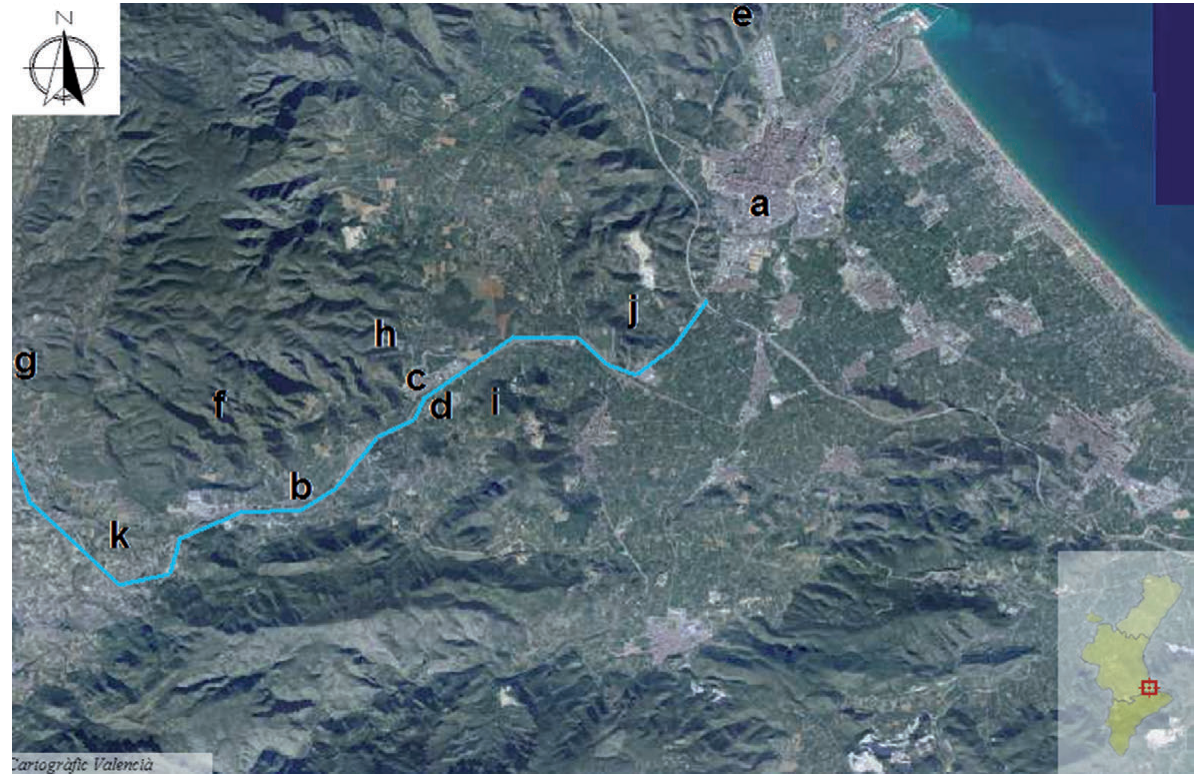

Figura 2: El corredor del río Vernissa. En los puntos: a. Gandía; b. Almiserat y Lugar Nuevo de San Jerónimo; c. Rotova; d. Alfahuir (núcleos de población); e. Bairén; f. Vilella; g. Chío / Luchente; h. Borró; i. Palma (recintos defensivos / castillos); j. Marchuquera, cierre del corredor; $k$. apertura del corredor hacia el interior de la provincia. (Fuente: TerraSit)
Vilella fue construido en la cima de una pequeña meseta rocosa de $413 \mathrm{~m}$ de altura, entre dos barrancos a partir de los cuales se desarrolla un estrecho paso conocido como Coll del Llautó, una vía de comunicación histórica. Tres de las cuatro caras de la meseta presentan un perfil recto e inaccesible.

El ámbito geográfico se define por la dirección de las últimas estribaciones de los sistemas prebéticos, perpendiculares a la costa, que dejan corredores de orientación O-E (interior-litoral) cada vez más anchos hasta dar paso a amplias llanuras litorales de formación aluvial (Segura y Carmona, 1999). A lo largo de uno de esos corredores fluye el río Vernissa, el cual vertebra un paso que comunica el interior del norte de la provincia de Alicante con la costa; la margen izquierda de este río es la más abierta, hallándose los recintos defensivos de época islámica sobre puntales (caso de Palma), mientras que la margen derecha es completamente montañosa, de modo que los refugios se encuentran encajados en el sistema de estrechos barrancos que predomina (caso de Borró y de Vilella).

\section{APROXIMACIÓN HISTÓRI CA}

El emplazamiento de Vilella cuenta con escasas referencias documentales. Aparece por primera vez en la Crónica o Llibre dels Fets del rey Jaime I, relato pormenorizado de la conquista cristiana del Sharq al-Andalus (luego reino de Valencia):

E quan açò fo passat, entram en la Vall de Bairèn, e parlam ab l'alcaid qui tenia lo castell de Bairèn, e ab aquells de Vilallonga, e de Borró, e de Vilella, e de Palma, qui eren castells de roca grans e forts. E dixeren-nos que, quan l'alcaid de Bairèn hauria feit pleit ab nós, que tots aquells de la vall se rendrien'.

En marzo de 1239, Jaime I llegó con sus tropas a la fortaleza costera de Bairén (Gandía) y, de inmediato, se entrevistó con su alcaide, llamado Avencedrell / Ibn Sidray (Guichard, 2001: 293) y con los alcaides de otros castillos y refugios de la zona. Éstos, tras la descomposición del poder almohade, debían haber quedado bajo la órbita de influencia de Bairén, convertido en punto preeminente del territorio o hisn. Se acordó una tregua de siete meses, tras los cuales se rindió Bairén y, con él, los emplazamientos de Villalonga, Borró, Vilella y Palma. El relato es confuso acerca de si Vilella poseía un alcaide propio o no, pero en caso de que lo tuviera, no se conoce su nombre ${ }^{3}$ y muy poco o nada recibiría de los

\footnotetext{
2 Trad. del a.: "Y cuando esto hubo sucedido, entramos en el valle de Bairén, y hablamos con el alcaide que tenía el castillo de Bairén, y con aquellos [alcaides] de Vilallonga, de Borró, de Vilella y de Palma, que eran castillos roqueros grandes y fuertes. Y nos dijeron que cuando el alcaide de Bairén hubiera pactado con Nos, que todos aquellos del valle se rendirían". De la edición de Ferrando i Francés, 1984.

3 Nunca se llega a conocer el nombre de los alcaides de menor rango. Una de las pocas excepciones la representa el caso de Carmoixent. Guichard opina que la aparición reiterada décadas después de la conquista de los nombres de ciertos alcaides en la documentación cristiana puede llevar a pensar en la existencia de una categoría "militar" de estos personajes. El alcaide de Carmoixent, llamado Abuceyt Abencablia, tenía el castillo durante la tercera revuelta de los musulmanes valencianos (1276-1277), pero acabaría por entregarlo a Pedro el Grande en 1277 o 1278 (Guichard, 2001: 593). Estos alcaides rurales siempre suelen recibir, tras la conquista, donaciones muy discretas por la transferencia de sus castillos a los cristianos. Suele tratarse de simples personajes preeminentes dentro de una pequeña aljama, normalmente la que ha construido el refugio o la más cercana a él.
} 
conquistadores a cambio de rendir el refugio, aparte de la permanencia en sus tierras, como venía siendo habitual en los pactos establecidos. Tras el cambio de jurisdicción, Vilella debió quedar abandonado ${ }^{4}$.

En 1258, Vilella vuelve a aparecer en la mención de las guarniciones cristianas encomendadas a Arnau de Foces y a sus alcaides, destacadas en los sitios de Benicadell, Carbonera, Bélgida, Montes, Rugat, Vilella, Borró y Palma, con motivo de la resistencia musulmana a la conquista ${ }^{5}$. La guarnición de Vilella se destinó a la protección del paso del Coll del Llautó y a evitar que el refugio fuese tomado por los musulmanes, donde podrían haberse hecho fuertes. Una vez pacificado el territorio, Vilella volvió a quedar abandonado; así lo demuestra que no aparezca en la relación de guarniciones del año 1260, la cual solo afecta a Benicadell y Palma (Bazzana y Guichard, 1980).

En el año 1261, el topónimo Vilella vuelve a aparecer en la documentación ${ }^{6}$, aunque en referencia a una alquería, hoy despoblada, del término de Luchente (Valencia), a unos $5 \mathrm{~km}$ del refugio. Es la primera y única vez que se menciona, lo cual nos lleva a pensar en una relación entre el edificio defensivo y los pobladores de este núcleo, aunque ignoramos de qué tipo.

Desde la segunda mitad del siglo XIII, pues, Vilella queda abandonado. El refugio permanecería ajeno a la investigación y no sería "redescubierto" hasta diciembre de 1978, durante el transcurso de una prospección aérea de la zona. Serían los investigadores franceses Pierre Guichard y André Bazzana quienes asociaran la imagen de una estructura desconocida con el Vilella de la documentación medieval, basándose en su localización (Bazzana y Guichard, 1980; Bazzana, 1983a, 1983b)7 Sin embargo, las limitaciones de la fotografía aérea de

\footnotetext{
4 Ni el contingente militar del momento de la conquista era suficiente para ocupar y mantener los numerosos recintos fuertes tomados a los andalusíes, ni la Corona disponía de los recursos económicos, ni siquiera mediante la donación a manos privadas, para mantenerlos activos y en buen estado. Aparte, no todos tenían importancia militar o geográfica como para destinar hombres y recursos a su ocupación; ese fue el caso de los refugios rurales, abandonados del mismo modo que los albacares de los complejos de mayor entidad (López Elum, 2002).

5 Archivo de la Corona de Aragón (A.C.A.), reg. 10, fol. 100 rv.

6 A.C.A., reg. 11, fol. 192 r.

7 La confusión en la historiografía es notable: en 1965, el historiador local Josep Camarena afirmaba que, tras la donación de Almiserà (Almiserat) en 1298 a Lorenzo d'Escala, éste construyó allí su propio castillo (Camarena, 1965: 38). El desconocimiento entonces de la localización de Vilella lleva a duplicar su existencia: "hacia el interior se escalonaban en profundidad los [castillos] de Palma, Borró (Rótova) y Vilella (Luchente). Otros dos de menor importancia, los de Villalonga y Almiserat, completaban el circuito defensivo de La Huerta" (Camarena, 1965: 25).
}

la época los condujeron a formular algunas hipótesis que hoy cabe revisar.

Actualmente es un Bien de Interés Cultural (BIC), con declaración genérica, sobre el cual no se plantea ningún tipo de actuación.

\section{EL RECI NTO DE VI LELLA}

El refugio de Vilella es hoy un recinto vacío, limitado por varios lienzos de tapia que forman un espacio amurallado de planta poligonal alargada en dirección E-O, con cierta forma de riñón (figuras 3 y 4). La muralla bloquea las caras norte, oeste y parte de la este de la meseta en la que se asienta el refugio. La cara sur carece de muros de defensa, pues aquí se aprovecha la orografía natural de la peña para ahorrar trabajo de construcción, como ocurre en otros refugios situados en altura (Bazzana, 2002). El único punto accesible se encuentra al norte, al final de un estrecho camino natural.

Las dos únicas unidades complejas del refugio son una torre situada al oeste y el sistema de ingreso en recodo al norte. Ambas estructuras se encuentran unidas por los lienzos de la cerca. La defensa del recinto se centra en ellas dos, no hallando ninguna otra estructura más.

Uno de los aspectos más llamativos del refugio es la ausencia de cisterna o aljibe para la recogida y almacenamiento de agua. No es algo habitual en los construcciones defensivas andalusíes, puesto que el aljibe es un elemento esencial para la supervivencia de los refugiados en caso de cerco o asedio ${ }^{8}$. Su ausencia plantea un grave problema para la ocupación efectiva de Vilella, ante lo cual cabe la posibilidad, por un lado, de que la cisterna haya desaparecido por completo o, por otra parte, que jamás llegara a existir. Si bien es cierto que existen diversas fuentes en los alrededores del refugio $^{9}$, la falta de aljibe convierte a Vilella en uno de los pocos recintos carentes de esta instalación.

En cuanto al registro cerámico, es escaso y el mayor porcentaje corresponde a fragmentos informes de teja cuya adscripción cronológica resulta muy difícil. Representa, sin embargo, la prueba de la existencia de estructuras techadas en el interior de Vilella, aunque no podamos

\footnotetext{
8 No obstante, desde que Bazzana y Guichard relacionaron el nombre de Vilella con estos restos hasta las últimas publicaciones, se ha tendido a señalar que sí hay un aljibe: "Es nota l'absència total de qualsevol classe d'edifici habitable de manera permanent. L'única construcció que apareix és l'aljub, instal-lat contra la muralla" (Bazzana, 1983a: 255). Se confunde la torre oeste con un depósito de agua.

${ }^{9}$ Agradecemos la información al respecto proporcionada por don José Signes Camarena, natural de Almiserat y buen conocedor del paraje donde el refugio se encuentra.
} 

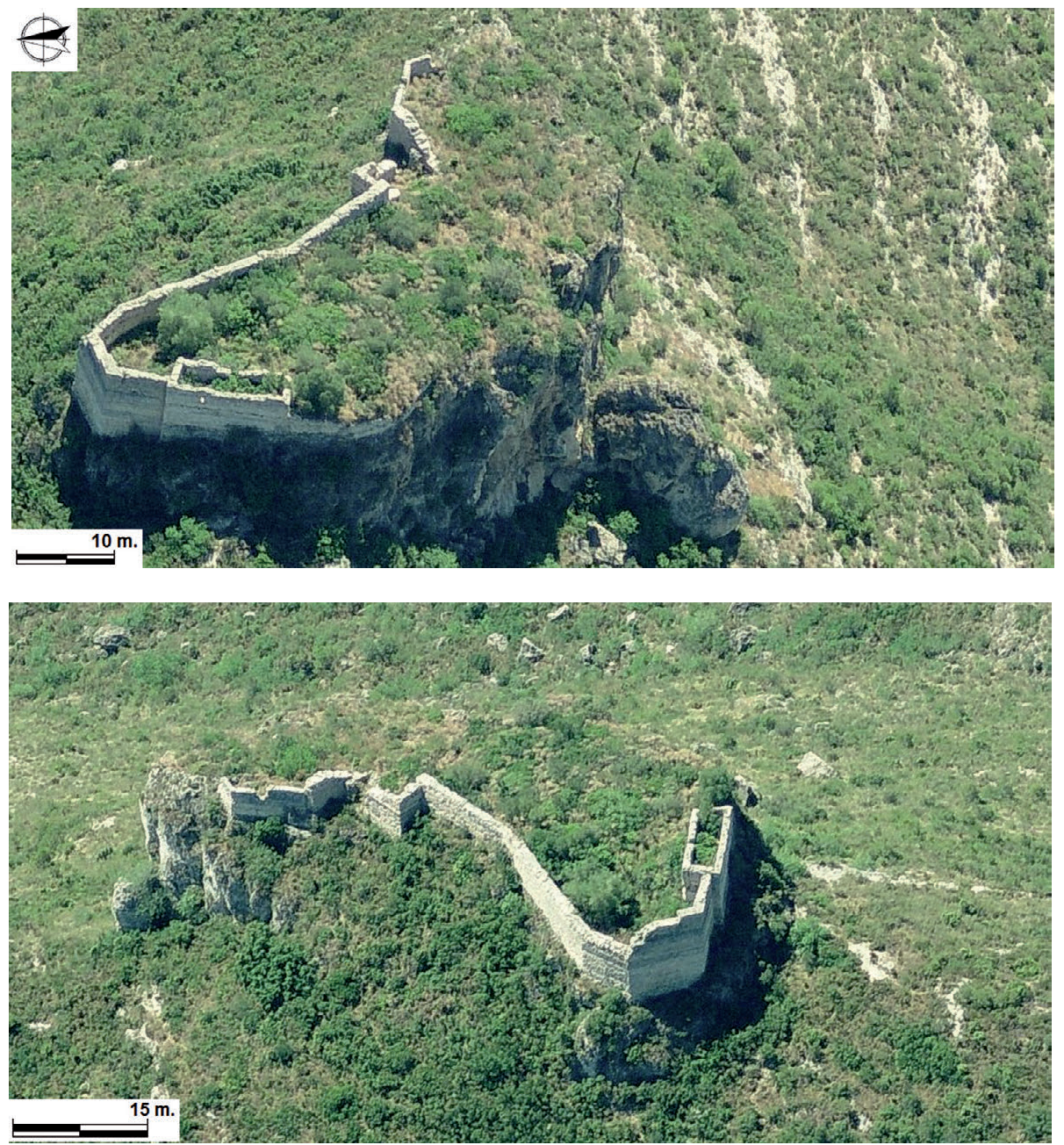

Figuras 3 y 4: Vista aérea del refugio de Vilella. En primer término, trazado de la cerca y sistema de ingreso. (Fuente: Goolzoom)

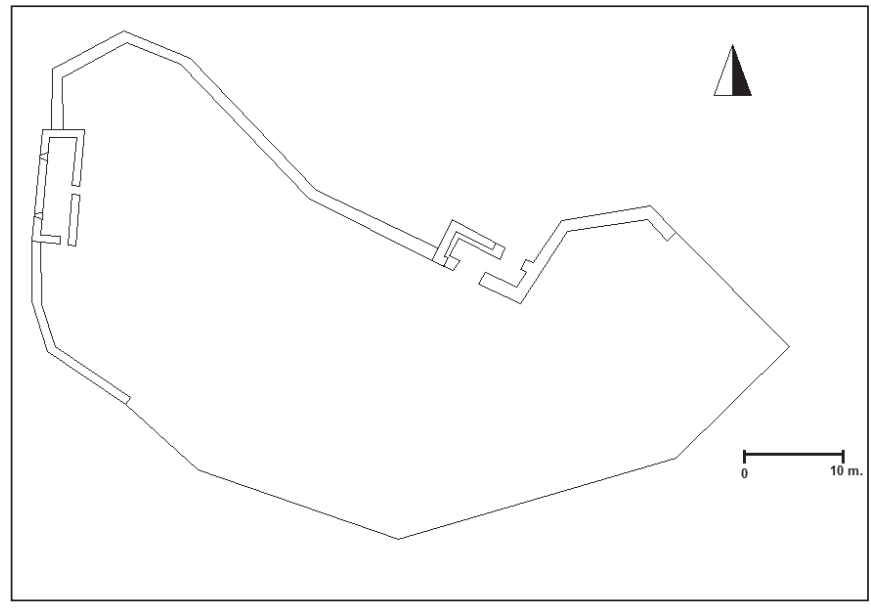

Figura 5: Plano del refugio de Vilella

decir a qué época pertenecerían ni cuál sería su naturaleza. El restante volumen cerámico está compuesto por galbos muy rodados y, en su mayor parte, sin decoración, de pasta anaranjada bícroma con desgrasante mineral grueso, $\mathrm{y}$ algún fragmento escaso vidriado en turquesa que nos sitúa a finales del siglo XII y comienzos del XIII. La escasez de material cerámico se debe, creemos, al corto espacio de tiempo que Vilella estuvo ocupado, según la documentación escrita, pero también a la inclinación de la meseta rocosa hacia el N-NO y hacia el $\mathrm{S}$, lo cual ha provocado, en el primer caso, la acumulación de sedimentos contra los muros de cierre y, en el segundo, el arrastre de materiales hacia la ladera $\mathrm{S}$ y el barranco que discurre a los pies.

El mayor volumen de información, pues, ha quedado en los restos arquitectónicos que se mantienen en pie.

\section{CONSI DERACI ONES SOBRE TÉCNICA CONSTRUCTI VA}

El estudio y documentación de los restos arquitectónicos de Vilella nos ha permitido obtener un importante registro de técnica constructiva. Mayoritariamente se empleó, como en todos los recintos defensivos del área ya señalada, la técnica del tapial, consistente en encofrados móviles de madera (tapiales) que se rellenan con tierra y otros materiales: cal o yeso, piedras, gravas, ladrillos 
y eventualmente madera o fragmentos de cerámica; la mezcla se compacta por capas con ayuda de un pisón. Vilella ofrece la posibilidad de ampliar el panorama de estudio de esta técnica de construcción, puesto que presenta diversas tipologías de tapia; junto a la técnica y materiales, ha sido posible, además, recuperar algunas secuencias de construcción y, sobre todo, diversas marcas e improntas asociadas al uso de los encofrados. Ello nos permite conocer de forma indirecta el tipo y variedad de cajones utilizados, así como las partes de las que estuvieron compuestos.

En menor proporción, los alarifes de Vilella hicieron uso de la mampostería, la cual, aun así, sigue siendo abundante. Fue utilizada, principalmente, para construir los zócalos de los muros de tapia y levantar las bases de regularización de los mismos en una meseta de superficies irregulares. De forma casi residual, la técnica de la mampostería aparece también en acabamientos y en parches de reparación.

La piedra labrada es prácticamente anecdótica. No hay evidencias de sillares, y la única estereotomía la representan los sillarejos, que se colocan solamente en ciertos puntos bajos de la estructura de la torre oeste, los muros del perímetro y el sistema de ingreso.

\subsection{Uso del tapial}

Salvo en zócalos y bases de regularización, aparte de otros pocos puntos, el refugio andalusí de Vilella se levantó mediante la técnica del tapial. Se utilizaron encofrados horizontales compuestos por tableros de barzones alternos (uno en el interior y otro en el exterior) y un cabecero de tablones verticales (figura 5). Los tableros estuvieron conformados por entre 4 y 6 tablones de altura variable (figura 26), hasta formar cajones de 86 centímetros de altura media (figura 23); se trata, en la mayoría de las once muestras claras tomadas, de cajones de módulo alto, entre 85 y 95 centímetros, derivados seguramente de la equivalencia de 2 codos mamuníes, de 47'14 centímetros cada uno (Graciani y Tabales, 2008: 137). El grosor de los cajones, en todos los casos, se encuentra entre los 70 y los 76 centímetros, pero este dato no lo consideramos relevante, dado que responde en cada caso a necesidades concretas relacionadas con la resistencia o la altura del paramento.

El resultado son tapias simples, con superposición de cajones sin ningún elemento entre ellos que los articule y aspecto de fábrica homogénea y monolítica (Graciani y Tabales, 2008: 136), interrumpida solamente, en algunos casos, por la presencia de pies de aguja. Se trata de uno de

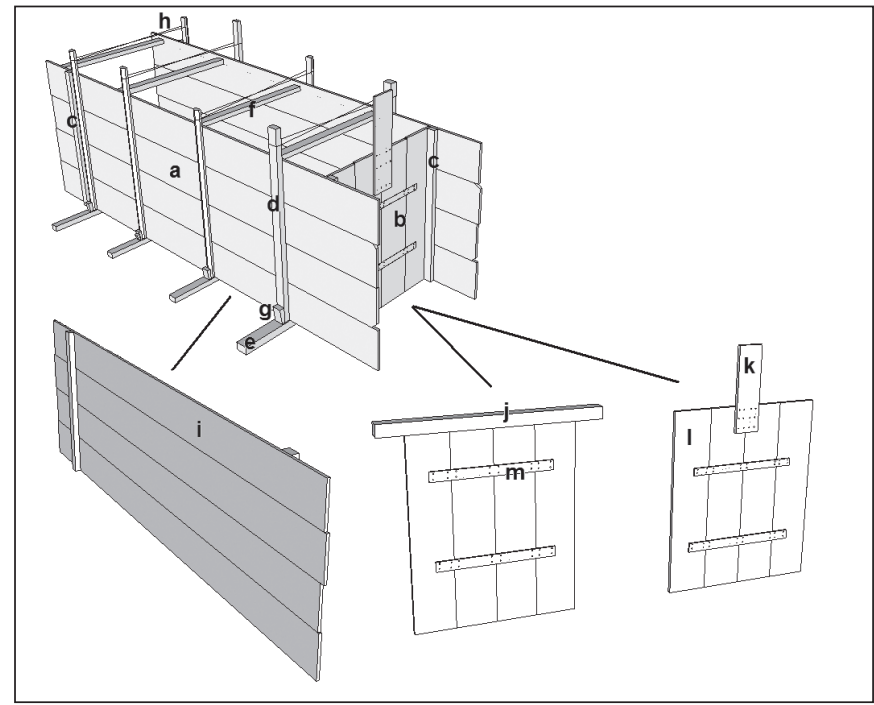

Figura 6: Partes de un encofrado: a. tablero o tapial; b. cabecero o puerta; c. barzón; d. costal; e. aguja; f. bastón; g. cuña; h. cuerda o lía; en el tablero, i. tablón; en los dos tipos de cabecero posibles, j. tope; k. tirador; I. tablón; m. pletina, que puede ser metálica o una tira de madera

los tipos de tapia más simples que existe; aunque escape a la zona geográfica que tratamos, tipos muy similares han sido datados en el área sevillana (Graciani, 2008a, 2008b, 2009; Graciani y Tabales, 2003, 2008; Tabales, 1999, 2000), murciana (Navarro y Jiménez, 2011) y granadina (Martín, 2008) desde época almohade. En nuestro caso, dado que sabemos que al final de la década de 1230 el refugio ya estaba construido, el límite se establece en época postalmohade (1228-1233/1245), con pervivencia algunos años después de la conquista por la utilización de alarifes musulmanes. Ayudan también a ofrecer una datación relativa algunos ejemplos locales, como son los llamados albacares de nuestra zona geográfica, abandonados por los cristianos tras la conquista a causa del poco interés que les suscitaban (Epalza, 1984); por tanto, esos recintos no llegaron a sufrir las reformas de las alcazabas o "celoquias" desde el segundo tercio del siglo XIII y, sobre todo, a lo largo del siglo XIV. Las cercas de los albacares presentan una técnica de ejecución y unos materiales idénticos al caso de Vilella, prefiriendo el tapial de bloques y áridos con sistema de agujas pasantes y remate simple de laja o bloque a otras soluciones técnicas bastante menos representadas. Hay que puntualizar, sin embargo, que los materiales por sí mismos son incapaces de aportar una adscripción cronocultural, puesto que la presencia o ausencia de unos u otros se encuentra condicionada por razones diversas tales como el tipo y sistema de construcción, la envergadura del edificio, la disponibilidad económica de un momento concreto, las exigencias mecánicas 


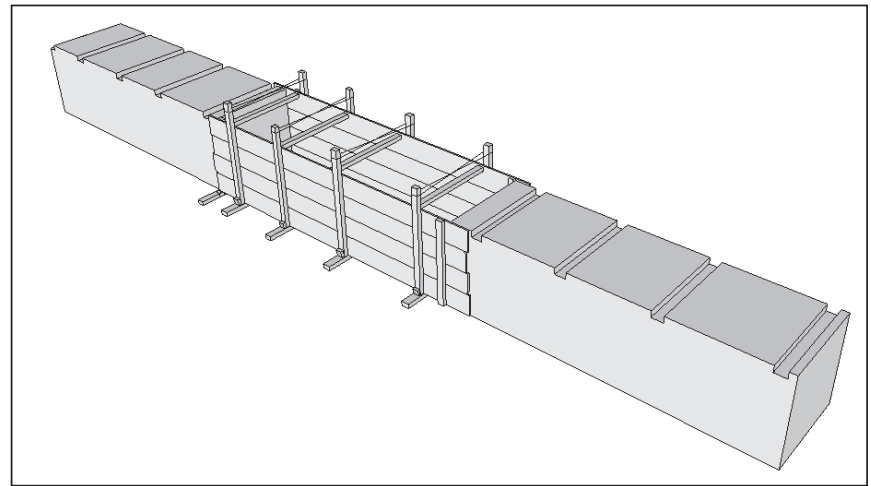

Figura 7: Montaje de un encofrado sin cabecero, entestado entre dos tapiadas finalizadas cuyos tapiales corrieron en sentido convergente hasta encontrarse; obsérvese cómo solapan los tableros

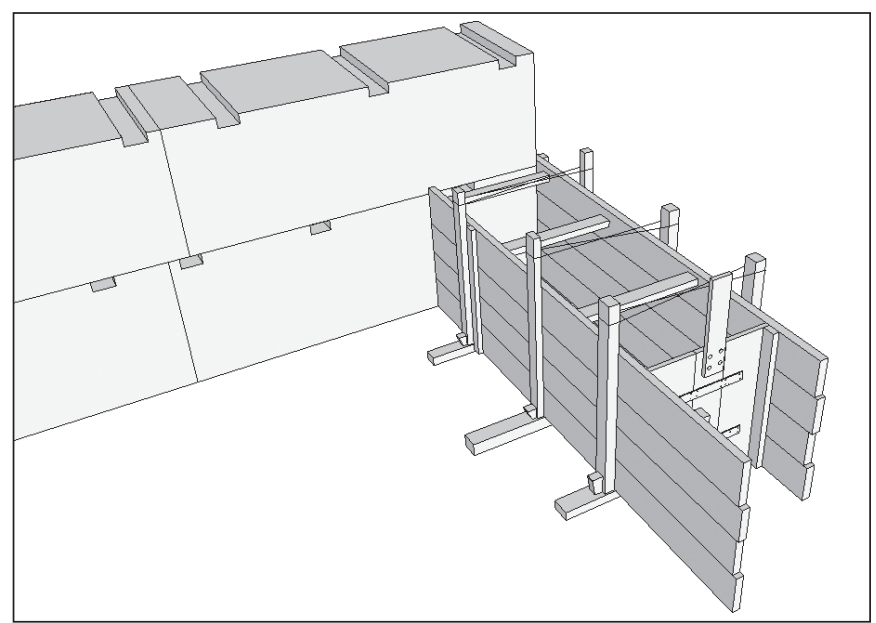

Figura 8: Propuesta de montaje de un encofrado para formar los ángulos de la cerca del refugio. Ante la falta de cabecero, pudo utilizarse un sistema de anillos y tirantes

$\mathrm{y}$, sobre todo, el acceso a unas u otras materias (Graciani y Tabales, 2008: 137). Es la observación del conjunto la que debe guiar la datación.

En Vilella, el sistema de agujas más utilizado es pasante; sus improntas, llamadas agujales ${ }^{10}$, aparecen en dos posiciones: bajo el hilo superior de los cajones o rompiendo éste, dependiendo de si se colocan los bastones antes o durante el vertido de la última tongada. En algunos cajones, los agujales marginales rompen o se pegan a los hilos verticales. No se ha podido documentar que en todos los casos se trate de agujas recuperadas, aunque parece ser

\footnotetext{
10 Aunque se ha utilizado de manera muy mayoritaria el término mechinal para designar el orificio de inserción de las agujas, el adecuado y correcto es agujal, quedando reservado el primero para otros sistemas de construcción: el DRAE lo define como "agujero cuadrado que se deja en las paredes cuando se fabrica un edificio, para meter en él un palo horizontal del andamio", aunque también ayuda a sustentar entramados de vigas. El mismo DRAE define, por su parte, el agujal como "agujero que queda en las paredes al sacar las agujas de los tapiales".
}

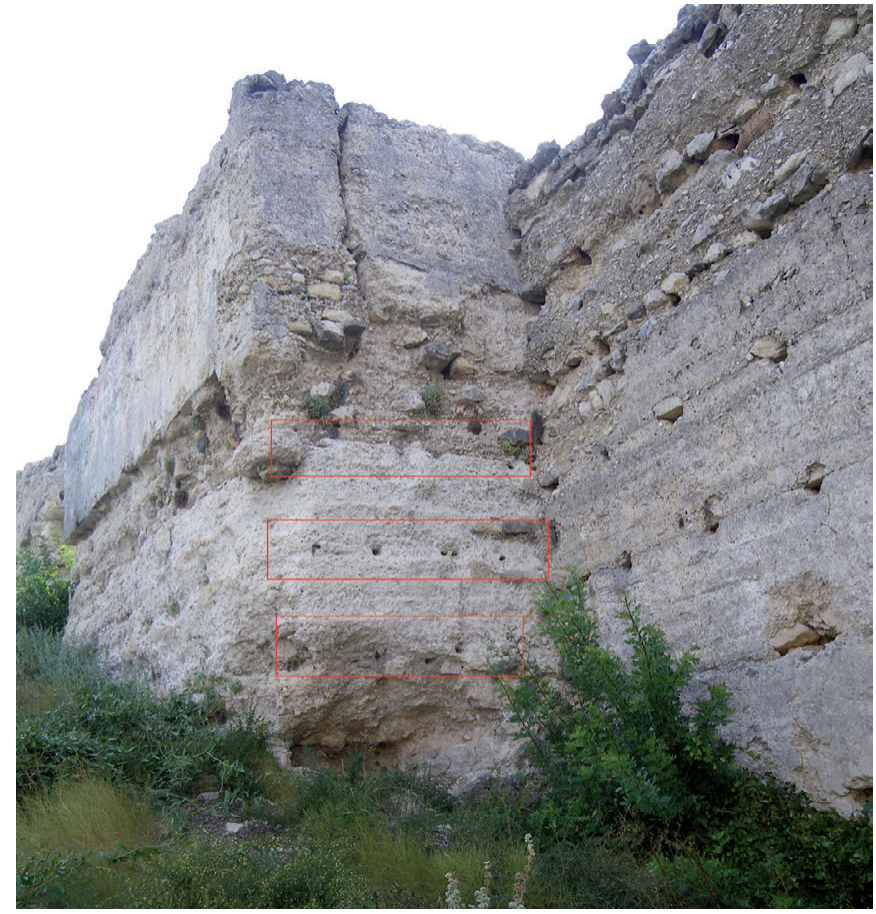

Figura 9: Distintas fábricas en el contacto entre la cerca NO y la torre oeste: el cuerpo superior es de tapia de mortero con bloques y áridos, mientras que el inferior es de tapia hormigonada. En los rectángulos, las líneas en que aparecen los agujales rectangulares de pequeño tamaño

la opción más usada. El sistema de agujas no pasantes se emplea en los laterales cortos de los cajones para montar a lo largo los encofrados superiores en el contrapeado de las esquinas: se practica una roza de profundidad variable en la que se inserta una aguja que ayuda al montaje del encofrado superior. No se han registrado evidencias de tirantes.

Tampoco ha sido posible determinar si las agujas empleadas fueron de madera o metálicas, aunque la primera opción es la más probable, dada la utilización de los recursos locales (en este caso, la madera) y el uso restringido del hierro en la Edad Media. En el interior de algunos agujales se han encontrado restos de madera de agujas perdidas.

Por lo que respecta a los cajones, se ha podido registrar el uso de tres modalidades de tapia distintas:

- modalidad que algunos autores llaman "hormigonada" u "hormigón de tapial" (Azuar, 1995; Graciani y Tabales, 2008; Martín, 2008): la hemos definido como una tapia de mortero de cal con áridos (proporción baja de gravas de tamaño no superior a los 3 centímetros de media, irregulares y de aristas vivas), rica en cal y pobre en tierra. Es muy compacta y de gran resistencia. Escasa o nula presencia de bloques en su composición. 
Se utiliza de manera preferente en las hiladas bajas de algunas estructuras por presentar una mejor resistencia al desgaste y a la capilaridad (figura 9).

- tapia de mortero con bloques y áridos (presencia media de cantos de pequeño tamaño y gravas de entre 3 y 5 centímetros, irregulares y de aristas vivas): la mezcla de mortero presenta también una mayor proporción de cal que de tierra; sin embargo el porcentaje mayor de la composición lo representan los bloques, calizos y de tamaño medio (entre 10 y 20 centímetros de media). No están regularizados, la mayoría muestran trazas de extracción o de reducción y muchos de ellos solamente se encuentran desbastados para facilitar el encaje y la colocación contra los tableros. Estos bloques se disponen entestados, con la cara más plana contra los tableros y una tendencia horizontal, en hiladas regulares y por tongadas alternas. Las tongadas de bloques presentan un grosor medio de 13 a 15 centímetros, mientras que las de mortero se sitúan en una media de 8 centímetros. Cada hilada de bloques fue presionada para que el mortero de la tongada inferior, sobre la que descansaban los bloques, se infiltrase entre los huecos; del mismo modo, las capas de mortero se presionaban con el mismo objetivo, tratando de evitar al máximo las bolsas de aire. Gracias al desplazamiento por presión, los bloques tienden a retirarse de los tableros lo suficiente para que entre ambos se filtre el mortero, creando una costra poco homogénea y de espesor variable, la cual a veces ni siquiera llega a cubrir por completo las caras de los bloques. Este tipo es el dominante en Vilella.

- tapia "calicostrada" o costrada: modalidad de la tapia de mortero con bloques y áridos. La mezcla de mortero y áridos supera la proporción de bloques; el mortero, al tiempo que rellena los huecos entre los bloques por la presión, se aplica con un espesor variable contra los tableros antes del vertido y compactado de las tongadas. Así se crea una capa de protección o costra que permanece tras el desencofrado.

Este tipo de tapias son consideradas recientes, y así lo creemos también nosotros, enmarcadas desde un momento indeterminado del siglo XI o comienzos del XII hasta la conquista del territorio valenciano, con perduración a lo largo del siglo XIII. Para esta fase reciente hemos observado, dentro de nuestra área geográfica, una generalización del uso de bloques en la composición de las tapias, en las construcciones fechadas entre la segunda mitad del siglo XII y la primera mitad del siglo XIII.
Por otra parte, la aparición en un mismo paramento o una misma estructura de distintas modalidades de tapia responde a necesidades estructurales; mientras que las tapias "hormigonadas" se utilizan en posiciones inferiores dada su mayor resistencia, las tapias con contenido de bloques aparecen en posiciones superiores. Éstas últimas suelen ser las que presentan la mayor cantidad de reparaciones y las que con mayor facilidad se desgastan una vez el edificio queda abandonado.

\subsection{Uso de la mampostería}

La de la mampostería es una técnica muy localizada, pero abundante: se encuentra principalmente en zócalos, cimentaciones y bases de regularización (figura 11), así como en reparaciones y parches realizados en los paramentos de tapia, aunque en algunos casos se utilizó también en acabamientos y alzado de muros (figura 10) ${ }^{11}$.

\footnotetext{
Tras la conquista cristiana, el tapial no se abandona, pero los paramentos exclusivamente de mampostería sí parecen más comunes en época cristiana, como ocurre en uno de los muros del recinto superior del castillo de Palma, o en los poblados moriscos de los valles interiores de la Marina Alta (norte de Alicante), donde la mampostería parece encofrarse (Torró e Ivars, 1990).
}

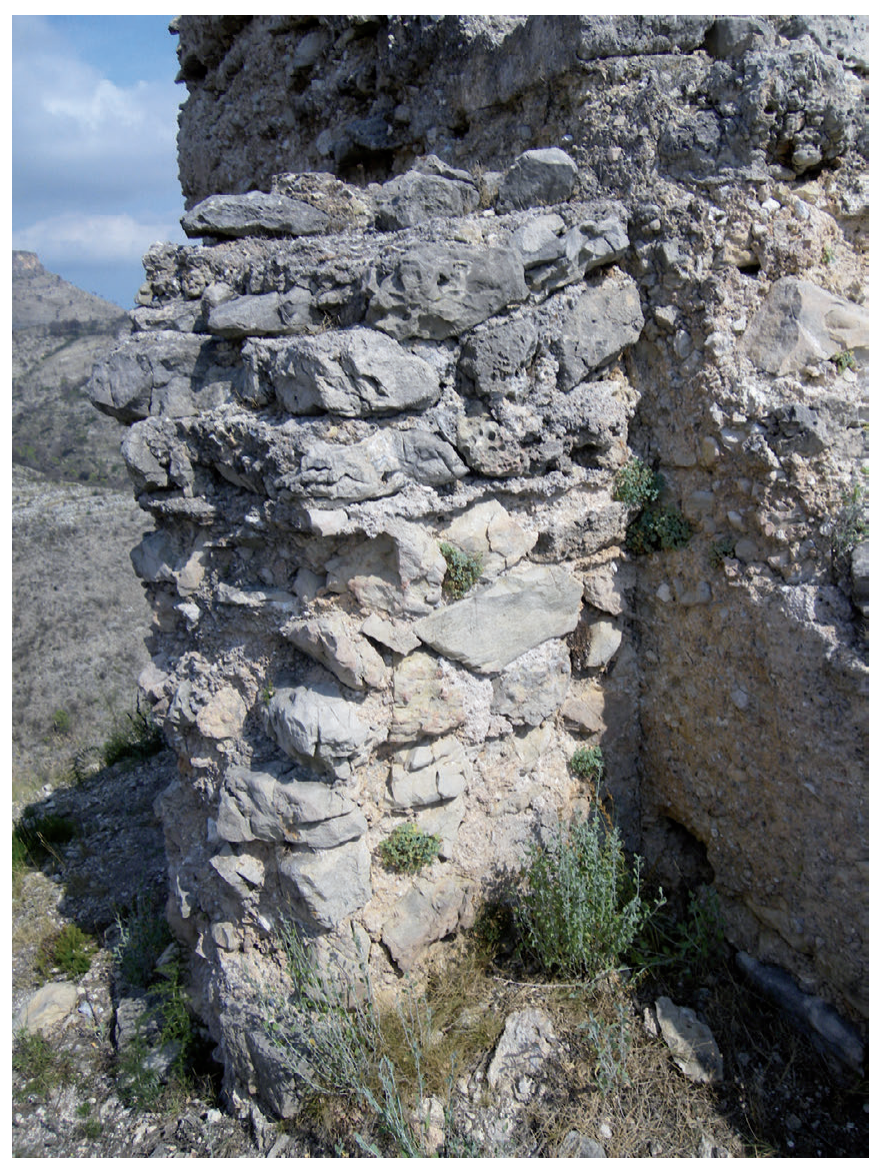

Figura 10: Muro de mampostería del sistema de ingreso 


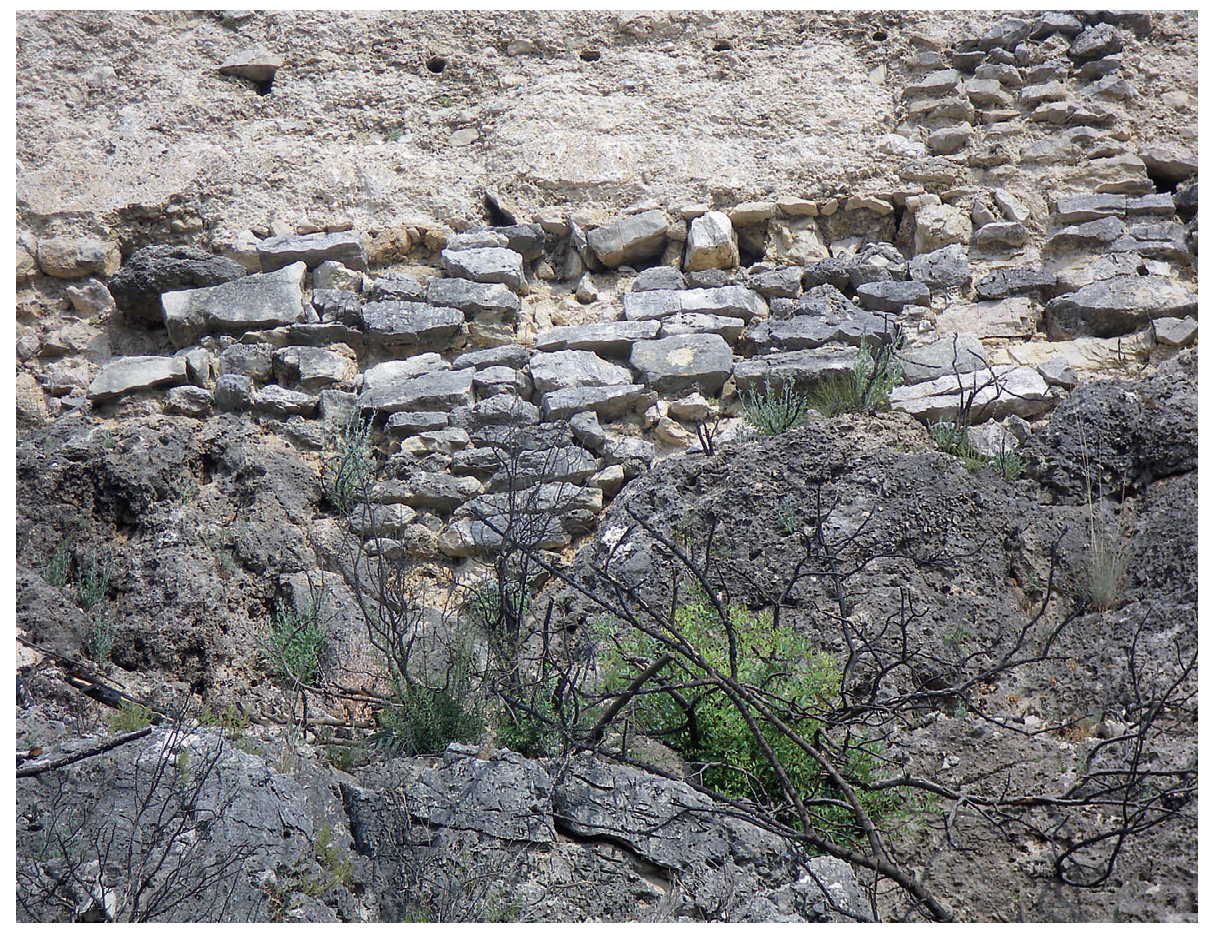

Figura 11: Mampostería regular cuyas hiladas se adaptan al contorno de la roca
La mampostería se define como una técnica o fábrica basada en la piedra recibida con mortero (López Elum, 2002, vol. II: 156). Aparece en todos los recintos defensivos, en mayor o menor grado. Basándonos en el registro, hemos establecido dos grandes divisiones:

- mampostería ordenada o concertada (figuras 10 y 11): los mampuestos o bloques presentan un orden regular, dispuestos en hiladas continuas de la misma altura. Normalmente suelen colocarse a plomo, la forma más habitual en las mamposterías encofradas, y en horizontal, con la parte larga y más plana descansando sobre las lechadas de mortero. Existe un tipo peculiar de mampostería concertada en la que se colocan en oblicuo o falso spicatum; más que como una herencia de las fábricas antiguas, hemos de buscar su causa en el deseo de ahorro de material constructivo, pues esta colocación favorece levantar las hiladas con un menor número de mampuestos. En Vilella no aparece, pero sí en construcciones de época cristiana (Torró e Ivars, 1990; Sánchez, 2010).

- mampostería desordenada o irregular: lo más habitual es que se trate de una fábrica libre (no encofrada) y oportunista (aprovechamiento máximo de los materiales disponibles). Los mampuestos se colocan tratando de formar hiladas regulares, interrumpidas por mampuestos o bloques de mayor tamaño (figura 12; obsérvese el zócalo); en ocasiones, la irregularidad es completa y resulta complicado o imposible definir hiladas. Ambos tipos se encuentran presentes en Vilella. No siempre las caras de estos alzados se disponen a plomo, aunque a veces ocurre. Cabe la posibilidad de que algunas fábricas irregulares fueran encofradas.

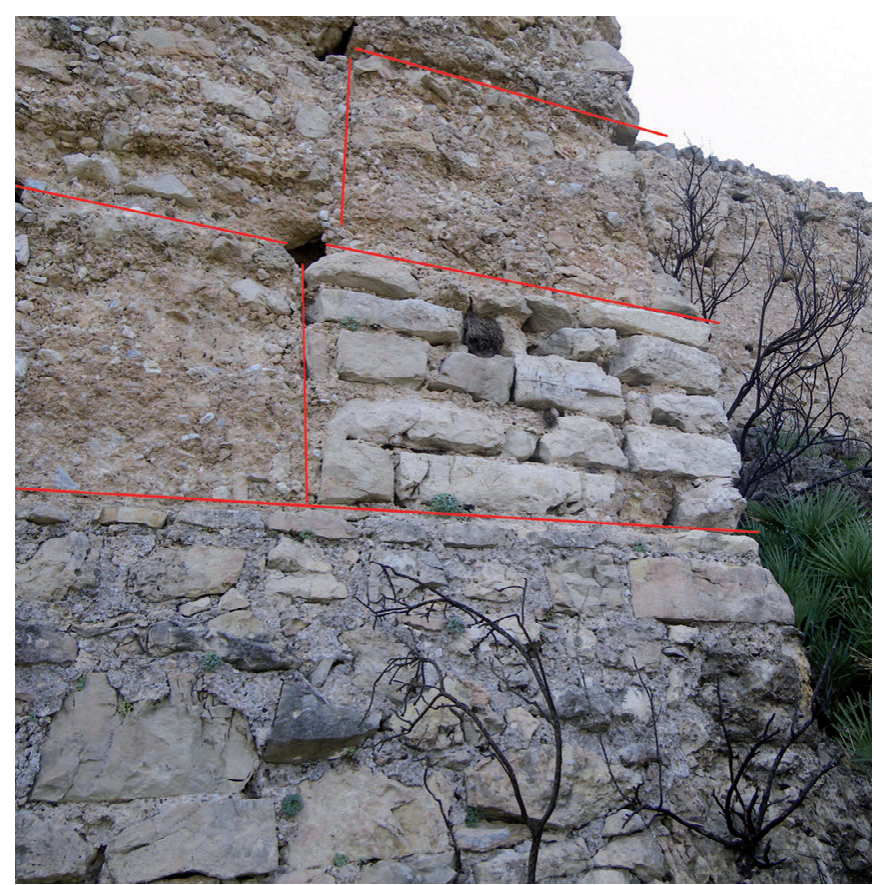

Figura 12: Refuerzo de sillarejos en el sistema de ingreso. En rojo se han marcado los hilos de los cajones. Abajo, zócalo de mampostería más o menos irregular 
La división certera entre mamposterías libres y encofradas resulta mucho más complicada. A veces se reconocen con facilidad por la existencia de improntas de encofrados (agujales, mayoritariamente) o por el plomo recto de las fábricas. No obstante, que no aparezcan esas impresiones no significa que no se encofrasen: debieron existir cajones sin sistema de agujas, sujetos desde el exterior por puntales, también usados para levantar algunos tipos de tapia en las zonas bajas de los paramentos. Esta consideración se basa también en el acabado exterior plano que adoptan las lechadas de mortero al rebosar (Torró e Ivars, 1990: 76).

\subsection{Uso del sillarejo}

El uso de bloques trabajados solamente se ha podido documentar en Vilella en dos refuerzos esquineros situados en el sistema de ingreso (figura 12) y en la torre oeste (figura 20), así como en varias de las bases de regularización constituidas por mampostería irregular, del tipo que tiende en la medida de lo posible a formar hiladas rectilíneas. Por su aspecto, no se trata de un trabajo muy especializado, pero su escaso número y el hecho de que no tengan un papel estructural determinado nos obliga a preguntarnos el por qué de las molestias en trabajarlos y si no se tratará de sillarejos reutilizados. Son bastante abundantes, sobre todo, en la parte inferior externa de la torre oeste (figura 20).

No es común encontrar este tipo de material constructivo entre los zócalos de mampostería, constituidos normalmente por mampuestos sin trabajar o simplemente regularizados para facilitar su encaje, aunque tampoco es del todo extraño. Sí es más común, sobre todo a partir de época cristiana, encontrar sillares o sillarejos para encadenar o como machones.

\subsection{Improntas de construcción}

Llamamos improntas o marcas de construcción a todas aquellas evidencias que quedan impresas en negativo contra los cajones de tapia por el uso de encofrados (también en las obras de mampostería encofrada). A través de estas improntas se puede establecer el tipo de caja utilizada, sus longitudes y sus elementos constitutivos, o al menos los que estuvieron en contacto con el material de construcción.

El abanico de improntas es amplio, pero se puede clasificar en dos grandes grupos, las asociadas a la caja de encofrado (tableros, cabecero y barzones) y los agujales.

Respecto al primer grupo, hemos documentado el uso de tableros formados por un mínimo de 4 y un máximo de 6 tablones de madera. La altura de cada uno de ellos es variable, y se relaciona con la altura total que tendrá el tablero, así como con la disponibilidad de tablones o de materia prima; esta altura se encuentra entre los $14 \mathrm{~cm}$ en el menor de los registrados y los $29 \mathrm{~cm}$, aunque son las medidas entre los 19 y los $21 \mathrm{~cm}$ las que más se repiten. La longitud de los tablones y, por tanto, de los tableros, parece ser más arbitraria. Hay que tener en cuenta los centímetros que se pierden en el montaje del encofrado, es decir, la distancia comprendida entre el cabecero y el extremo del tapial, y que resulta imposible de cuantificar salvo en los casos en los que el cabecero no se monta y se aprovecha todo el encofrado.

Las improntas de barzones no son tan comunes. En todo el recinto hemos podido identificar únicamente dos; como otras marcas de barzón conocidas, presentan una altura idéntica a la del cajón. Pertenecen a encofrados formados por tableros de barzones alternos y aparecen en los casos en los que no se monta el cabecero porque el encofrado puede ser encajado entre dos tapiadas ya terminadas. La impronta de barzón suele aparecer en las tapiadas de las esquinas, así que es un buen indicador de la dirección en que corre el encofrado: nos informa de que esa tapiada ha sido la última de la hilada y posterior a aquella con la que formará ángulo en la esquina. Cuando estas improntas no aparecen, como en la práctica totalidad de las cajas, se debe a que el cabecero está montado, puesto que éste reposa por el interior contra los barzones internos.

La impresión del barzón puede tener forma semicircular o cuadrangular/rectangular. Al desencofrar, estos huecos solían rellenarse con grava, cascotes o mortero y luego enlucirse para proteger la fábrica.

La primera de estas improntas se identificó en el punto de muestra número 11: tiene sección semicircular, 6 ' $5 \mathrm{~cm}$ de profundidad y $8 \mathrm{~cm}$ de anchura, con una separación respecto al extremo de $40 \mathrm{~cm}$. La longitud total de esta tapiada se ha estimado en $316 \mathrm{~cm}$, medida a la que es probable que se aproximen muchos de los encofrados utilizados en Vilella, de los que solamente podemos medir la parte útil. El segundo barzón es algo menor, de $5 \mathrm{~cm}$ de profundidad, $6 \mathrm{~cm}$ de anchura y también sección semicircular. Fue localizado en el punto de muestra número 16.

Bastante más escasas en general son las improntas dejadas por los cabeceros. En Vilella aparecen dos en el lateral derecho del vano de acceso $\mathrm{E}$ a la torre oeste, uno sobre otro. Son idénticos, miden $76 \mathrm{~cm}$ de anchura (como el muro) y están formados por tres tablones verticales. Esta configuración no es una norma, sino que responde a la anchura de la que se va a dotar al paramento y al acceso a tablones de determinado tamaño. 
Por último, documentamos una impronta de función indeterminada en el lienzo $\mathrm{N}$ de la muralla $\mathrm{E}$, sobre el hilo superior de la segunda hilada de cajas. Se hunde $3 \mathrm{~cm}$ respecto al plomo del paramento, tiene forma rectangular y se encuentra incompleta. Conserva algo desplazado del centro un orificio circular no pasante de 3 $\mathrm{cm}$ de diámetro (figura 13). Su forma y acabado indican una ejecución a molde previa al desencofrado, tal vez un refuerzo interno del juego ${ }^{12}$; es la única impronta de estas características que conocemos no solo en Vilella, sino también en el resto de edificios defensivos rurales de nuestra área de estudio.

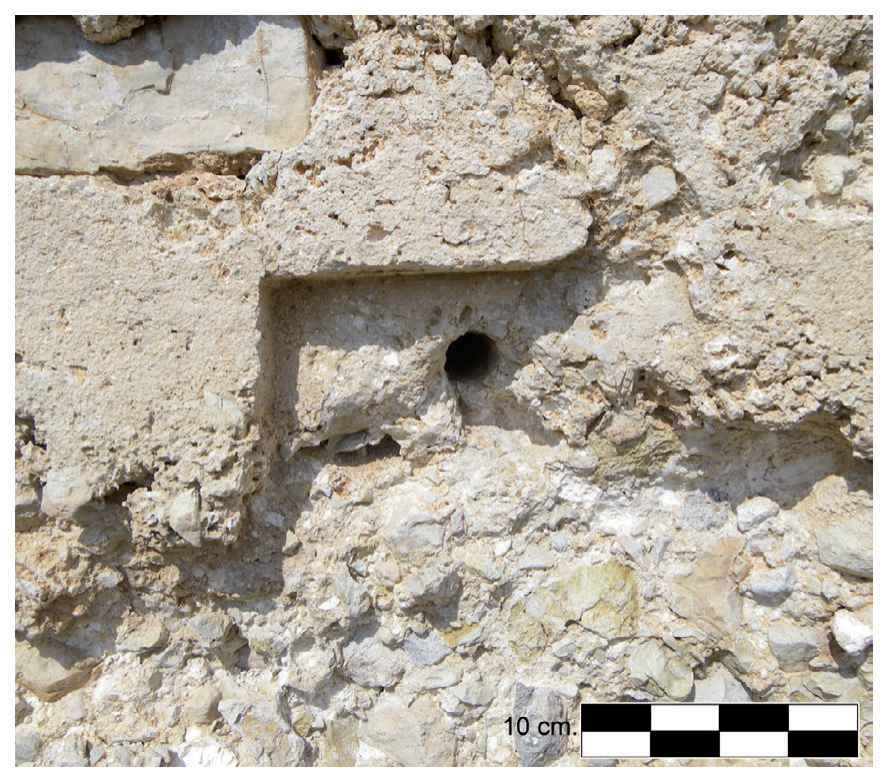

Figura 13: Impronta de función indeterminada en la cara interior del paramento NE de la cerca

La categoría de los agujales agrupa el mayor número de improntas que se pueden registrar en cualquier construcción en tapia. La gran diversidad de los que encontramos en Vilella nos ha permitido realizar una aproximación tipológica a este tipo de improntas (figura 14) y una descripción de cada categoría. Esperamos que, con el tiempo y una mayor cantidad de datos y ejemplos, se pueda llegar a establecer relaciones cronotipológicas (figuras 16 y 17):

- agujales cuadrados o rectangulares sin remate (figura 14.1): son poco habituales y su adscripción poco fiable, puesto que el mortero de rebose puede haber cubierto el remate. En Vilella son de aguja pasante.

12 Hemos de mostrar a este respecto nuestro más sincero agradecimiento a Josep Torró y a Ferran Soldevila por el interés mostrado a la hora de tratar de identificar esta impronta, aunque desgraciadamente no se ha podido llegar a ninguna conclusión satisfactoria.

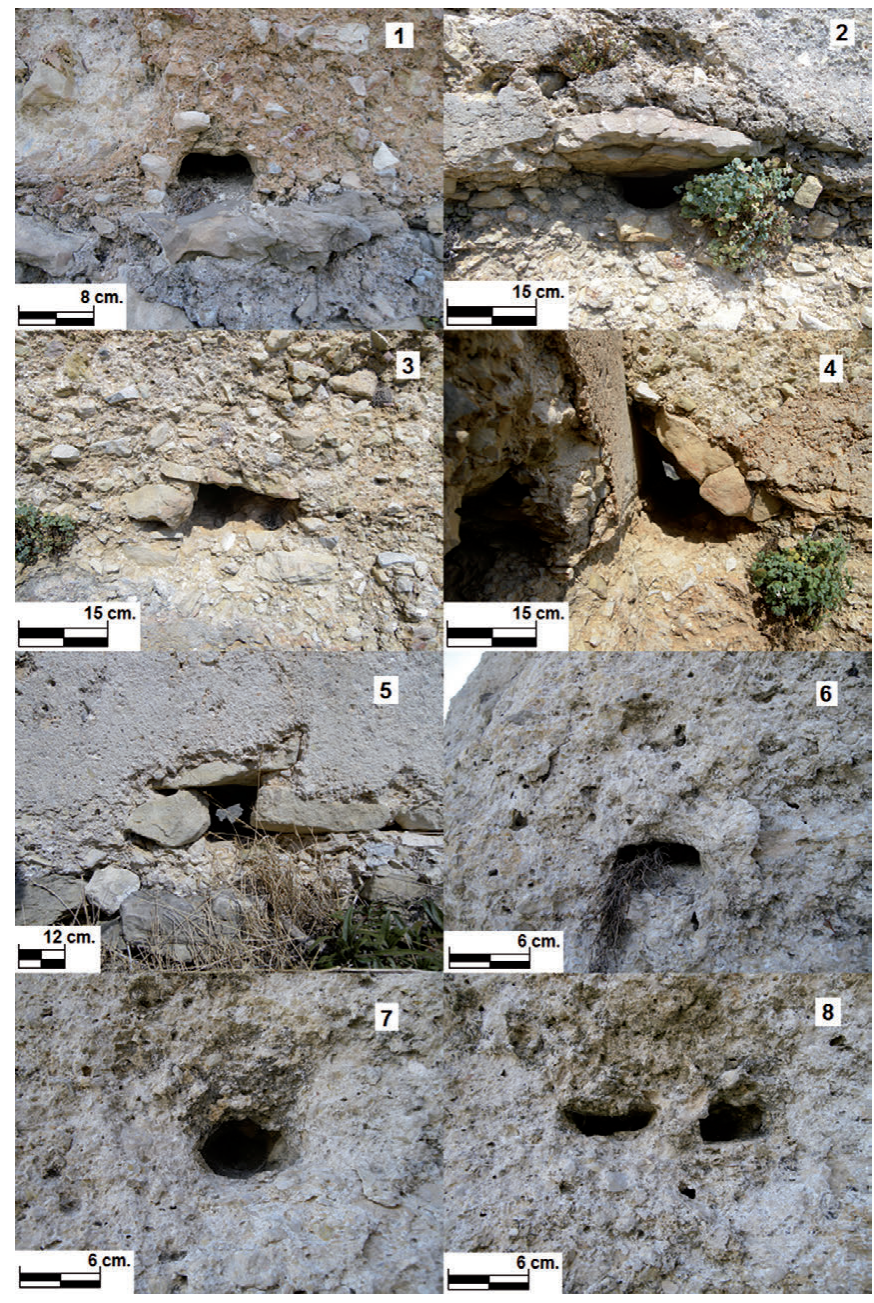

Figura 14: Diferentes tipos de agujales documentados en Vilella

\begin{tabular}{|c|c|c|c|c|}
\hline TAPIADA & POSICIÓN & LONGITUD & ALTURA & GROSOR \\
\hline$\# 1$ & $1^{\mathrm{a}}$ hilada & $307 \mathrm{~cm}$. & $80 \mathrm{~cm}$. (incomp.) & $70 / 76 \mathrm{~cm}$. \\
\hline \#2 & $1^{\mathrm{a}}$ hilada & $248 \mathrm{~cm}$. & $86 \mathrm{~cm}$. & $70 / 76 \mathrm{~cm}$. \\
\hline \#3 & $2^{a}$ hilada & $230 \mathrm{~cm}$. & $86 \mathrm{~cm}$. & $?$ \\
\hline$\# 4$ & $2^{\mathrm{a}}$ hilada & $304 \mathrm{~cm}$. & $86 \mathrm{~cm}$. & $?$ \\
\hline$\# 5$ & $1^{a}$ hilada & $252 \mathrm{~cm}$. & $60 \mathrm{~cm}$. (incomp.) & $?$ \\
\hline$\# 6$ & $1^{\mathrm{a}}$ hilada & $285 \mathrm{~cm}$. & $58 \mathrm{~cm}$. (incomp.) & $?$ \\
\hline$\# 7$ & $3^{a}$ hilada & $316 \mathrm{~cm}$. & $86 \mathrm{~cm}$. & $?$ \\
\hline$\# 8$ & $3^{a}$ hilada & $212 \mathrm{~cm}$. & $86 \mathrm{~cm}$. & $?$ \\
\hline$\# 9$ & $2^{\mathrm{a}}$ hilada & $232 \mathrm{~cm}$. & $84 \mathrm{~cm}$. & $?$ \\
\hline$\# 10$ & $1^{\mathrm{a}}$ hilada (int.) & $278 \mathrm{~cm}$. & $85 \mathrm{~cm}$. & $76 \mathrm{~cm}$. \\
\hline$\# 11$ & $1^{\mathrm{a}}$ hilada (int.) & $320 \mathrm{~cm}$. & $80 \mathrm{~cm}$. (incomp.) & $76 \mathrm{~cm}$. \\
\hline
\end{tabular}

Figura 15: Medidas y posición de las tapiadas tomadas como referencia

Normalmente se asocian a sistemas de aguja perdida, puesto que la presión del material y la expansión de la madera con la humedad vuelven luego muy complicada la extracción de la aguja. Documentados en el punto 2 (figura 19).

- agujales cuadrados o rectangulares con remate de piedra simple - bloque (figura 14.5): es el tipo más 


\begin{tabular}{|c|c|c|c|c|c|c|c|c|c|c|}
\hline & \begin{tabular}{|l|} 
Cuadrado o \\
rectangular sin \\
remate de piedra
\end{tabular} & \begin{tabular}{|l|} 
Cuadrado con \\
remate de piedra \\
simple - bloque \\
\end{tabular} & \begin{tabular}{|l|} 
Cuadrado con \\
remate de piedra \\
simple - laja
\end{tabular} & \begin{tabular}{|l|}
$\begin{array}{l}\text { Cuadrado con } \\
\text { remate tipo } \\
\text { "tejadillo" }\end{array}$ \\
\end{tabular} & \begin{tabular}{|l|}
$\begin{array}{l}\text { Cuadrado con } \\
\text { remate de laja } \\
\text { y bloque }\end{array}$ \\
\end{tabular} & \begin{tabular}{|l|} 
Cuadrado con \\
remate oblicuo \\
de laja o bloque \\
\end{tabular} & Circular & $\begin{array}{l}\text { Rectangular de } \\
\text { pequeño tamaño }\end{array}$ & $\begin{array}{l}\text { Subtipo: remate de } \\
\text { bloques apuntados }\end{array}$ & Indeterminados \\
\hline $\begin{array}{l}\text { Ingreso- } \\
\text { muro E }\end{array}$ & 1 & & & & & & & & & 2 \\
\hline $\begin{array}{l}\text { Ingreso- } \\
\text { muro NO }\end{array}$ & 2 & 6 & & 1 & 2 & 7 & 1 & & & 2 \\
\hline $\begin{array}{l}\text { Ingreso - } \\
\text { muro O inf. }\end{array}$ & & & 1 & & & 1 & & & & 3 \\
\hline $\begin{array}{l}\text { Ingreso- } \\
\text { muro O sup. }\end{array}$ & & 4 & & & 6 & & & & & 1 \\
\hline $\begin{array}{l}\text { Muralla E - } \\
\text { lienzo N }\end{array}$ & 1 & 22 & & & & & 2 & & & \\
\hline $\begin{array}{l}\text { Muralla E - } \\
\text { lienzo NE }\end{array}$ & & 3 & 1 & & & & 1 & & & 3 \\
\hline $\begin{array}{l}\text { Muralla E - } \\
\text { lienzo O }\end{array}$ & 1 & 5 & & & 4 & 2 & & & 2 & 4 \\
\hline $\begin{array}{l}\text { Enjarje } \\
\text { ingreso }\end{array}$ & & 5 & 1 & & 3 & 3 & & & & 1 \\
\hline $\begin{array}{l}\text { Muralla O- } \\
\text { lienzo NE }\end{array}$ & 2 & 13 & 5 & & 1 & 7 & & & & 2 \\
\hline $\begin{array}{l}\text { Muralla O- } \\
\text { lienzo NO }\end{array}$ & & 25 & 4 & 1 & 5 & 6 & & & 1 & 15 \\
\hline $\begin{array}{l}\text { Muralla O - } \\
\text { lienzo O }\end{array}$ & & 23 & & 1 & 3 & 11 & & & 2 & 10 \\
\hline $\begin{array}{l}\text { Torre oeste - } \\
\text { muro } \mathrm{N} \text { ext. }\end{array}$ & & 1 & & & & 1 & 1 & 10 & & \\
\hline $\begin{array}{l}\text { Torre oeste- } \\
\text { muro E ext. }\end{array}$ & & 1 & 1 & & & & 1 & 8 & & \\
\hline $\begin{array}{l}\text { Torre oeste - } \\
\text { muro O int. }\end{array}$ & & 14 & 2 & & & & & & & \\
\hline $\begin{array}{l}\text { Torre oeste - } \\
\text { muro O ext. }\end{array}$ & & 28 & & & & & & 35 & & 12 \\
\hline $\begin{array}{l}\text { Torre oeste - } \\
\text { muro } \mathrm{N} \text { int. }\end{array}$ & & 9 & 1 & & & & & & & \\
\hline $\begin{array}{l}\text { Torre oeste - } \\
\text { muro S int. }\end{array}$ & & 5 & & & & 1 & & & & \\
\hline TOTAL & 7 & 164 & 16 & 3 & 24 & 39 & 6 & 53 & 5 & 55 \\
\hline$\%$ & $1^{\prime} 88 \%$ & $44^{\prime} 08 \%$ & $4^{\prime} 30 \%$ & 0'8 \% & $6^{\prime} 45 \%$ & $10^{\prime} 48 \%$ & $1^{\prime} 61 \%$ & $14^{\prime} 24 \%$ & $11^{\prime} 34 \%$ & $14^{\prime} 78 \%$ \\
\hline
\end{tabular}

Fgura 16: Tipo, posición y número de los agujales contabilizados como muestra en Vilella

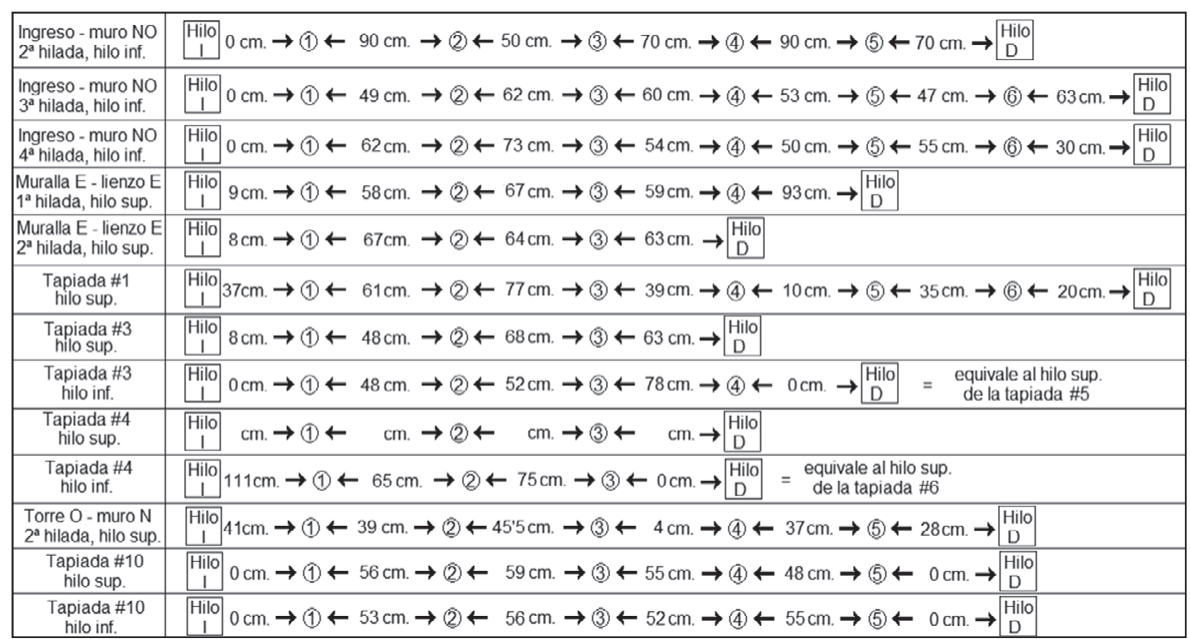

Figura 17: Esquema de los patrones de separación entre agujales en los paramentos tomados como referencia común, pues utiliza los mismos bloques que forman parte del ánima de la tapia para cubrir el mechinal. Como en el siguiente tipo, aparece a veces con refuerzos laterales de bloques que en ocasiones pertenecen a pies de aguja. Comunes en los puntos 3, 4, 6-11 y 13-16 (figura 19).

- agujales cuadrados o rectangulares con remate de piedra - laja (figura 14.2): su porcentaje también es alto, tanto en Vilella como en otros edificios similares. Ignoramos si el hecho de escoger un remate de bloque o laja encierra una intencionalidad o se debe a simple oportunidad, puesto que no hemos hallado relación entre uno y otro y la anchura de los agujales. El remate se realiza con una laja de tendencia plana, de mayor longitud que altura. Comunes en los puntos 3, 4 y 6-11 (figura 19). 


\begin{tabular}{|c|c|c|c|c|}
\hline TABLONES & TAPIADA \#2 & TAPIADA \#3 & TAPIADA \#7 & TAPIADA \#11 \\
\hline 6 & $14 \mathrm{~cm}$. & - & - & - \\
\hline 5 & $13 \mathrm{~cm}$. & $?$ & - & $21 \mathrm{~cm}$. \\
\hline 4 & $14 \mathrm{~cm}$. & $?$ & $19 \mathrm{~cm}$. & $19 \mathrm{~cm}$. \\
\hline 3 & $16 \mathrm{~cm}$. & $?$ & $21 \mathrm{~cm}$. & $23 \mathrm{~cm}$. \\
\hline 2 & $14 \mathrm{~cm}$. & $19 \mathrm{~cm}$. & $29 \mathrm{~cm}$. & $17 \mathrm{~cm}$. \\
\hline 1 & $10 \mathrm{~cm}$. & $24 \mathrm{~cm}$. & $17 \mathrm{~cm}$. & $?(5 / 6 \mathrm{~cm} . ?)$ \\
\hline
\end{tabular}

Figura 18: Medidas de los tablones de los tapiales

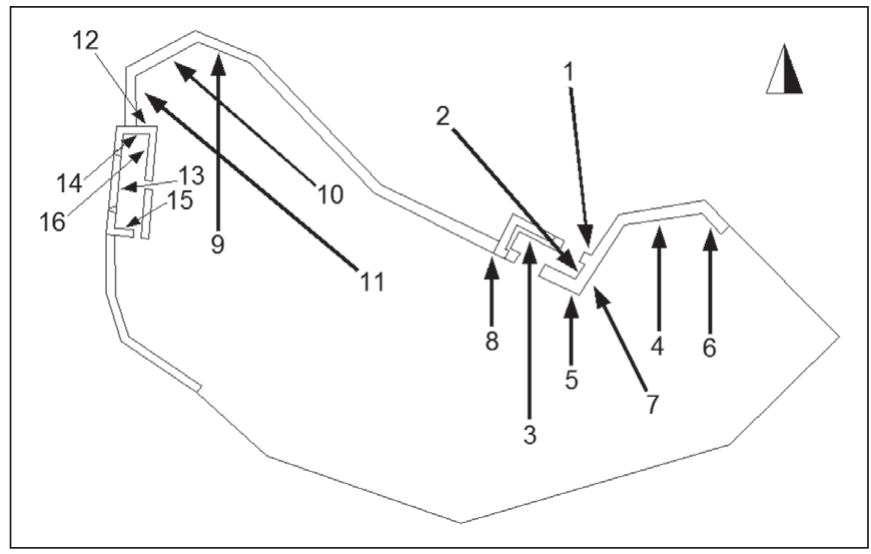

Figura 19: Croquis con los distintos puntos de referencia tomados para el estudio

- agujales cuadrados o rectangulares con remate tipo "tejadillo": resultan también un tipo bastante común. Están formados por dos lajas en oblicuo, cuyos extremos se apoyan, formando un ángulo (como en un tejado a dos aguas). Hemos creído conveniente aportar una subcategoría, a la que hemos llamado de bloques apuntados: el remate está formado siempre por dos bloques de extremo apuntado y colocados en oblicuo, de forma que entran en contacto por arriba (forma ${ }^{\wedge}$ ) o en ángulo invertido (forma v). No suelen ser numerosos. Aparecen en los puntos 3 y 9-11 (figura 19).

- agujales cuadrados o rectangulares con remate de laja y bloque (figura 14.3): formados por una laja, normalmente en posición oblicua, que descansa uno de sus extremos sobre un bloque colocado en horizontal. En general, no abundan. Aparecen, sobre todo, en el punto 3 (figura 19).

- agujales con remate oblicuo de laja o bloque (figura 14.4): tienden a tener forma apuntada, aunque en ocasiones se puede reconocer la sección cuadrada o rectangular del hueco. Aparecen, en la mayoría de los casos, asociados al comienzo de las tapiadas, apoyándose contra el frente corto del cajón ya terminado, por lo que son buenos indicadores de dirección; raras veces aparecen a mitad de tapiada. Documentados en los puntos 3, 4, 6 y 9-11 (figura 19).

- agujales circulares (figura 14.7): a pesar de ser muy comunes en otros edificios, en Vilella resultan escasos, lo cual nos podría encaminar en un futuro hacia el planteamiento de un marcador cronológico basado en la presencia/ausencia de este tipo de improntas. En ocasiones se las ha relacionado con cronologías cristianas y agujas metálicas ${ }^{13}$, aunque es una hipótesis discutida; en el caso que sean de madera, puede que se trate de ramas del entorno sin trabajar. Se asocian siempre con agujas pasantes. Aparecen en el punto 12 (figura 19).

- agujales rectangulares de pequeño tamaño: sin remate, no son demasiado comunes (figura 14.6). Se trata de orificios de pocos centímetros de anchura y altura, no siempre pasantes, y que aparecen tanto en obras andalusíes como cristianas ${ }^{14}$. Debemos incluir dos subtipos: los rectangulares de pequeño tamaño, algunos de ellos con ángulos en forma de cuarto de circunferencia, y los rectangulares de pequeño tamaño asociados en parejas (figura 14.8), que pueden aparecer en horizontal (cara externa del paramento $\mathrm{N}$ de la torre oeste) o superpuestos, el inferior en horizontal y el superior en oblicuo (cara externa del paramento $\mathrm{O}$ de la torre oeste); la función de estos pares resulta por ahora desconocida. Todos ellos se han documentado en el punto 12 (figura 19).

- agujales indeterminados: el desgaste continuo provoca que esta categoría sea abundante en todo el recinto.

En ocasiones, estas improntas no vienen determinadas por la sección o forma de las agujas, sino de los bastones, las piezas que se colocan entre los dos tableros en el interior del encofrado para contrarrestar la fuerza de presión que ejercen los costales. Hay tantos como agujas por caja. Se colocan en la parte superior del encofrado, de forma que, al verter la última tongada de material, compactarla y retirarlos, dejen rozas de un diámetro algo mayor que las agujas para facilitar la inserción de éstas (Font e Hidalgo, 1991: 52). En otros casos en que no existen agujales, se procede al montaje de pies de aguja.

\footnotetext{
13 "En ocasiones se empleaban agujas de metal. Éstas tenían la ventaja de extraerse una vez terminado el tapial. La señal que [...] dejaban en las fachadas era la de su silueta o contorno (cuadrada o rectangular en el primer caso [de madera] y circular en el segundo [de metal])". (López Elum, 2002, vol II: 158). Sin embargo, como ya hemos indicado, esta hipótesis se encuentra muy discutida. Hoy por hoy no hay pruebas arqueológicas que la avalen.

14 Aparte de en Vilella, hemos comprobado su existencia en la torre extrema del recinto oriental del castillo de Bairén en Gandía (Sánchez, 2010: 151) y, aunque se halle fuera de nuestra área de estudio, en la torre de Santa Ana de Sagunto (Valencia), intervenida en el año 2011 por el arqueólogo Francisco Blay García (ARCA S.L., y a quien agradecemos el acceso a la misma durante los trabajos). Esta torre se construyó con encofrados circulares y horizontales, usando un tipo de tapia costrada con bajo contenido en bloques y una alta proporción de árido grueso. Los agujales son cuadrangulares y rectangulares en todos los casos y sin remate que, cuando aparece, es simple con bloque. Sin embargo, aparecen algunos agujales rectangulares de pequeño tamaño en torno a los 2'5 cm de altura y 6'5 de anchura; solamente en un caso se documentó el subtipo de orificios superpuestos, con el superior en oblicuo. La construcción de esta torre podría encontrarse entre los siglos XII y XIII.
} 


\section{CIRCUITO AMURALLADO}

En el momento del estudio, dividimos la cerca del recinto de Vilella en cuatro sectores con el objetivo de facilitar su registro y la posterior ordenación de los datos: sector NE, sector N, sector O-NO y sector SO. En todos los casos, la técnica constructiva es la misma: encofrados de tapia horizontales, monolíticos, sobre zócalos y bases de regularización de mampostería. Los paramentos mejor conservados, en el sector O-NO, llegan a alcanzar una altura superior a los siete metros. No se ha conservado ningún resto de crestería, si es que lo hubo, ni tampoco evidencias de que hubiera podido existir un adarve: los muros tienen el mismo grosor en la base y en el final, y no se han encontrado mechinales que pudieran haber sujetado una pasarela, ni con vigas ni mediante tirantes. Así pues, los paños de Vilella cumplieron la sola función de cierre, reservándose la de defensa para la torre oeste y el sistema de ingreso.

Las cajas de tapia fueron colocadas contrapeadas, aunque en algunos puntos presenten hilos verticales coincidentes. La construcción de los lienzos se realizó en zig-zag, adaptándolos al máximo al contorno de la meseta. Entre un lienzo y otro no existe relación de traba, sino de apoyo, formando ángulos de entre 45 y $60^{\circ}$ en el interior, y 135 a $150^{\circ}$ en el exterior: durante la ejecución, los tableros de los encofrados se montaron desplazados, el exterior entestado contra el frente corto de la tapiada finalizada, y el interior apoyado contra el frente largo interno (figura 7). Este tipo de montaje de los tapiales dejaba ángulos interiores difíciles de apisonar, de forma que en muchas de las esquinas que forman los lienzos existen mazacotes de mortero mal prensados (figura 9).

El sector NE está dividido en los lienzos $\mathrm{O}$ (que forma parte del sistema de ingreso), $\mathrm{N}$ y E. Creemos relevante señalar aquí una peculiaridad en el lienzo $\mathrm{N}$ que soluciona un problema constructivo algo complejo: en este punto de la plataforma, la roca madre se eleva por encima del plano para luego descender hacia el este formando un abrupto desnivel en forma de escalón. La solución de los alarifes consistió en crear un plano artificial con el que solventar la irregularidad del terreno, que sirviera a la vez como zócalo o cimentación, y que regulara la altura de los cajones, puesto que, sobre el escalón, la primera hilada de tapial se corresponde con la tercera una vez sobrepasado éste. Para ello, en primer lugar se procedió a preparar un plano de trabajo sobre el afloramiento rocoso mediante una lechada de mortero de cal con áridos finos, sobre la cual se montó un pie de aguja constituido por una sola hilada de bloques (paso 1 de la secuencia de construcción); una vez regularizado el plano horizontal, se preparó el plano vertical, donde se forma el escalón, para poder encajar el encofrado, así que los constructores colocaron dos grandes bloques al comienzo del escalón para acabar de lograr un plano completamente horizontal y formar un ángulo recto; se construyó al mismo tiempo un murete de mampuestos, dispuestos sin demasiado orden, con los que rellenar las irregularidades de la arista vertical (paso 2). Los huecos restantes entre los bloques y entre los mampuestos fueron colmatados con el vertido de mortero de cal con áridos y cantos (paso 3). Una vez logrados dos planos lo suficientemente regulares, comenzó la construcción con encofrados desde la parte más baja del desnivel, entestando contra el plano vertical el encofrado para la primera tapiada de la hilada inferior (paso 4), levantándola de $\mathrm{O}$ a E. Una vez alzadas las dos hiladas más bajas, los constructores comenzaron a montar los encofrados sobre el plano horizontal y el pie de aguja, también de $\mathrm{O}$ a $\mathrm{E}$, entestando la primera caja contra el lienzo O; esta hilada, al correr hacia el E, constituiría la tercera hilada de altura del paño (paso 5).

La recuperación de esta secuencia constructiva completa nos permite aproximarnos al proceso arquitectónico del refugio. Comprobamos, pues, que tras la idea de improvisación o sencillez que se atribuye a la técnica del tapial, hubo planificación previa.

\section{SI STEMA DE I NGRESO}

Se trata del único punto por el cual se puede acceder al interior del recinto de Vilella. Es un sistema no excesivamente complejo, encuadrado en la categoría de accesos en recodo mediante torre, y reforzado por la orografía de la propia peña del refugio. Tiene planta rectangular con dos vanos no enfrentados: cuando se accede a la estructu$\mathrm{ra}$, es necesario realizar un giro a la derecha para encarar el segundo hueco (figura 20). Su estado de conservación es muy deficiente: presenta patologías generales extensibles a los demás paramentos de Vilella, como efectos

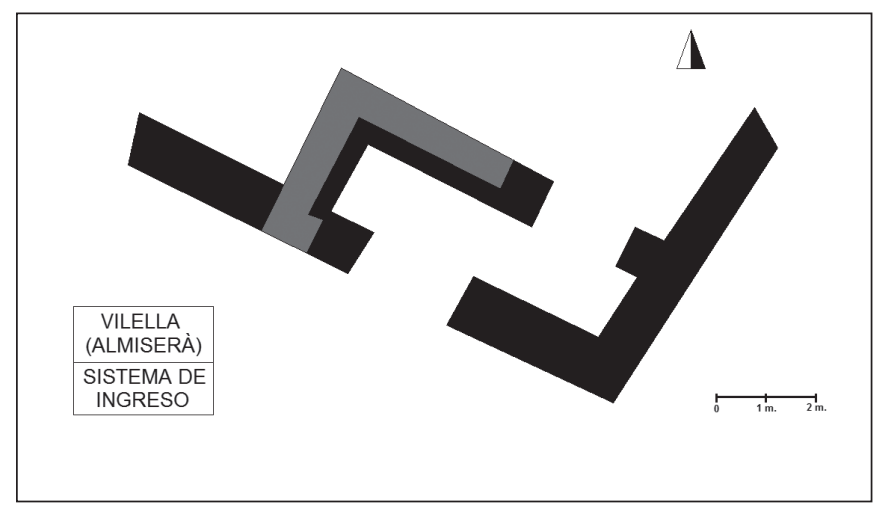

Figura 20: Croquis de la planta del sistema de ingreso. En gris, el segundo cuerpo de la torre-portal 


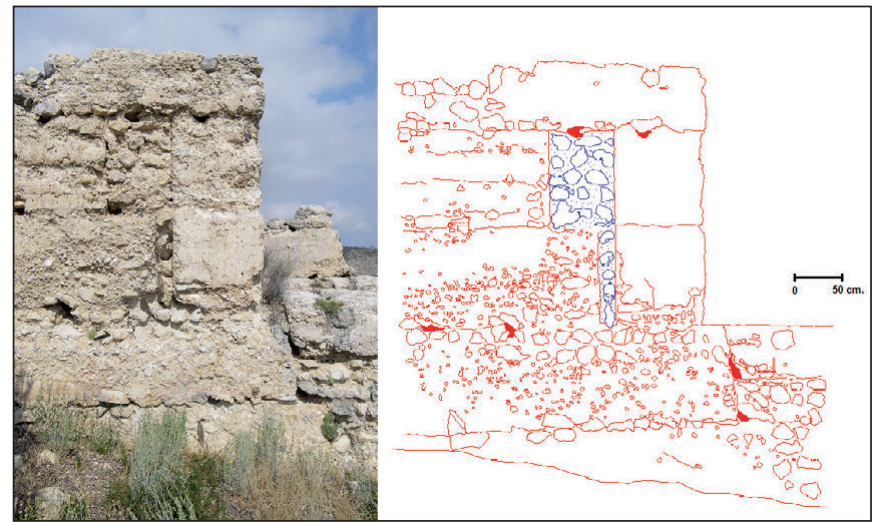

Figura 21: Encuentro de la cerca $\mathrm{N}$ con el sistema de ingreso y representación gráfica

de derrubio en las partes inferiores, pérdida de materia constructiva, caída de las hiladas superiores, pérdida de recubrimientos y lavado de las aristas.

Se han sugerido varias propuestas de interpretación para esta estructura, desde muros paralelos dotados de adarve hasta un pasillo con impedimento flanqueado por una torre (Bazzana, 2002: 36, ver plano). Sin embargo, la hipótesis que planteamos es que se trate de una torreportal, edificio bastante común en las construcciones defensivas de época almohade (Márquez y Gurriarán, 2008). Presenta dos cuerpos bien diferenciados (figura 23), visibles todavía en los paramentos $\mathrm{N}$ y $\mathrm{O}$, dado que el alzado conservado en los demás es mínimo.

El primer cuerpo está formado por cuatro hiladas de tapia (de abajo hacia arriba $84,80,84$ y $54 \mathrm{~cm}$ de altura en el paramento NO), con un grosor de $120 \mathrm{~cm}$. Sobre

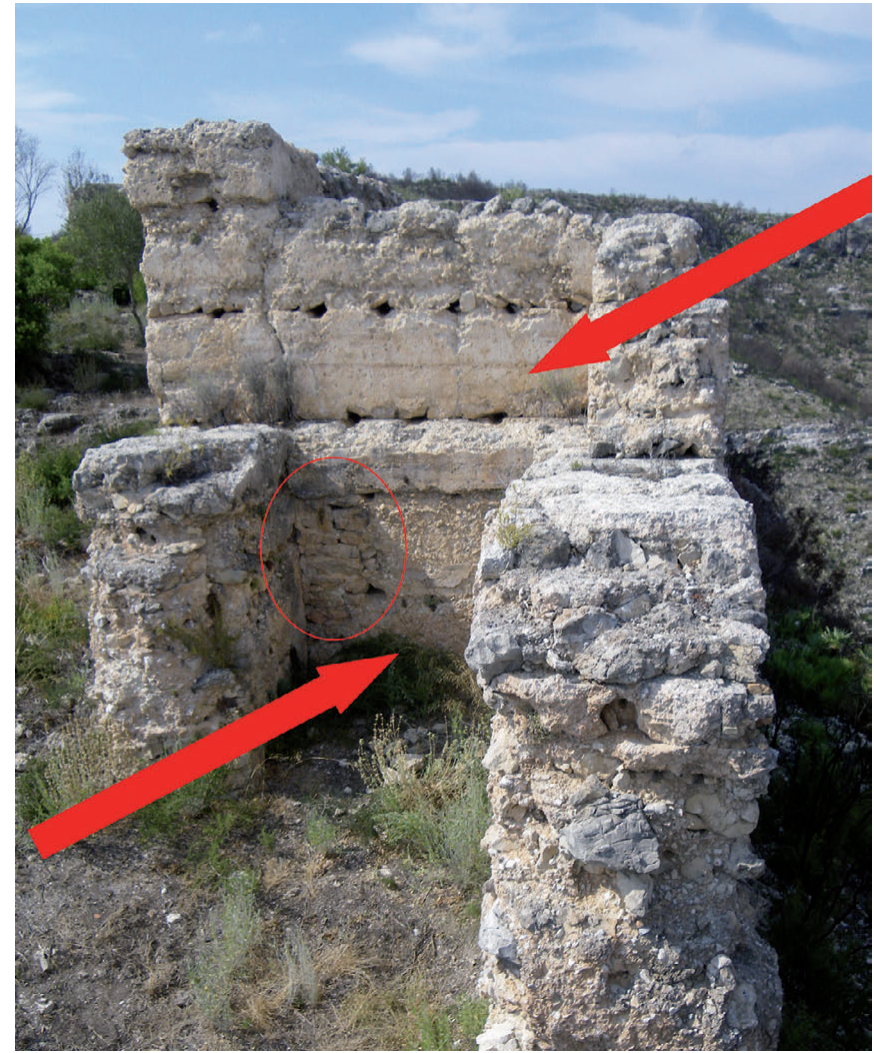

Figura 23: Interior de la torre-portal: las dos flechas marcan el cuerpo superior y el inferior, y el círculo el parche de reparación de mampuestos

él se alzan los restos de dos hiladas de tapia (en el muro $\mathrm{O}$, pero solo una en el $\mathrm{NO}$ ), con un grosor de $90 \mathrm{~cm}$, colocadas a plomo en la cara externa y dejando en el interior una bancada. Se construye con tapia de mortero

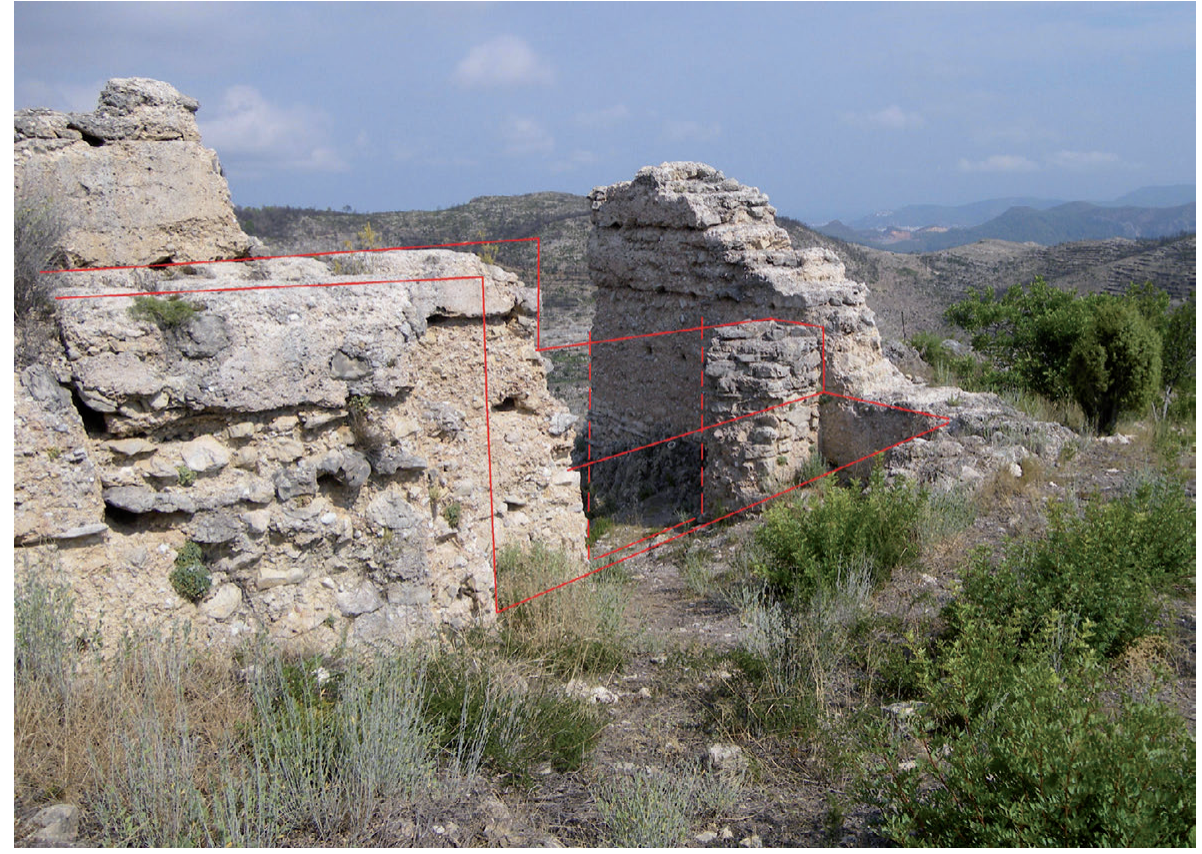

Figura 22: Vista del sistema de ingreso desde el interior del refugio 
con bloques y áridos, salvo el paramento NE: se trata de un pequeño muro incompleto (debido a la conservación) de $120 \mathrm{~cm}$ de anchura, $80 \mathrm{~cm}$ de longitud y cerca de 2 $\mathrm{m}$ de altura, realizado con mampostería ordenada y aparentemente libre. Se apoya contra el paramento E y pertenece al lateral izquierdo del vano exterior. Su fábrica se podría explicar por su longitud escasa, para lo cual no fue necesario montar un encofrado de tapia, solucionando el problema mediante un alzado de mampostería. $\mathrm{Su}$ altura original debió coincidir con la del vano, superado el cual el alzado volvería a ser de tapia.

La altura de dos hiladas del segundo cuerpo, con evidencias de hiladas perdidas, nos obliga a descartar su interpretación como parapeto de terraza o de adarve. Creemos que son los restos de una segunda planta de la torre portal, a la cual se accedería mediante una escalera de madera. La bancada que queda, debido al estrechamiento de este cuerpo $(90 \mathrm{~cm}$ frente a los 120 del inferior), sirvió para el montaje del forjado del segundo piso, mediante vigas de madera apoyadas en los paramentos $\mathrm{N}$ y S. Ignoramos si habría más cuerpos por encima del segundo, puesto que no han quedado evidencias.

El carácter simultáneo de la construcción de Vilella se ve interrumpido por la aparición de una segunda fase en la cara interna del paramento $\mathrm{O}$, una reparación o parche. Ocupa buena parte del alzado del primer cuerpo y se sitúa cercana a la esquina con el paramento SO. Se realizó con mampuestos y bloques colocados en hiladas regulares y recibidos con mortero de cal. Resulta imposible adscribir este parche a una cronología precisa: puede que se trate tanto de un fallo en la construcción que hubo de ser arreglado con relativa inmediatez o, de forma creemos que más probable, de un trabajo de reparación tras el primer período de abandono del refugio. De cualquier modo, estos retoques de la tapia mediante mampostería dispuesta en bataches resultan comunes en los edificios de tapia.
También en mampostería, aunque utilizando sillarejos más o menos escuadrados, encontramos en la esquina $\mathrm{O}$ de la cara externa del paramento NO un refuerzo o machón encofrado, idéntico a otro que aparece en posición similar en la torre oeste (figuras 12 y 24). Ocupa la primera hilada. Los sillarejos forman cinco líneas regulares en horizontal, que alternan con lechos finos y de grosor desigual de mortero de cal con áridos. Guarda las mismas proporciones que las tapias, $120 \mathrm{~cm}$ de anchura y $84 \mathrm{~cm}$ de altura. No creemos que se trate de un forrado externo solamente, sino más bien de un refuerzo localizado en dos puntos (sistema de ingreso y torre oeste) que los alarifes debieron considerar débiles o más expuestos al desgaste, para contrarrestar la presión ejercida por la estructura sobre la esquina. Por ahora no conocemos otros machones cortos de estas características y cronología en ningún otro edificio defensivo rural de nuestra zona de estudio.

Las relaciones entre los paramentos son de traba, salvo en el caso del muro de mampostería NE, el cual se apoya. Sin embargo, la unión del paramento SO con el lienzo de cerca $\mathrm{N}$ presenta un sistema que creemos interesante señalar: se contabilizan cinco hiladas de tapia costrada y de mortero con bloques y áridos, con una altura en torno a los 80-86 cm. Presenta dos llamativos acabamientos en mampostería en las hiladas tercera y cuarta, para solventar algunas deficiencias constructivas en el sistema de enjarje. Estos acabamientos fueron realizados con mampuestos (figura 16), colocados tratando de formar líneas regulares: el de la tercera hilada, al que hemos llamado A, mide apenas $15 \mathrm{~cm}$ de longitud, mientras que el de la cuarta hilada o B mide $70 \mathrm{~cm}$ de longitud. En ambos casos, la altura y la anchura son idénticas a las de las hiladas de tapia. Su función es la de rellenar los huecos que quedaron al tratar de trabar el lienzo de cerca con el sistema de ingreso mediante la colocación de cajas longitudinales y transversales: se

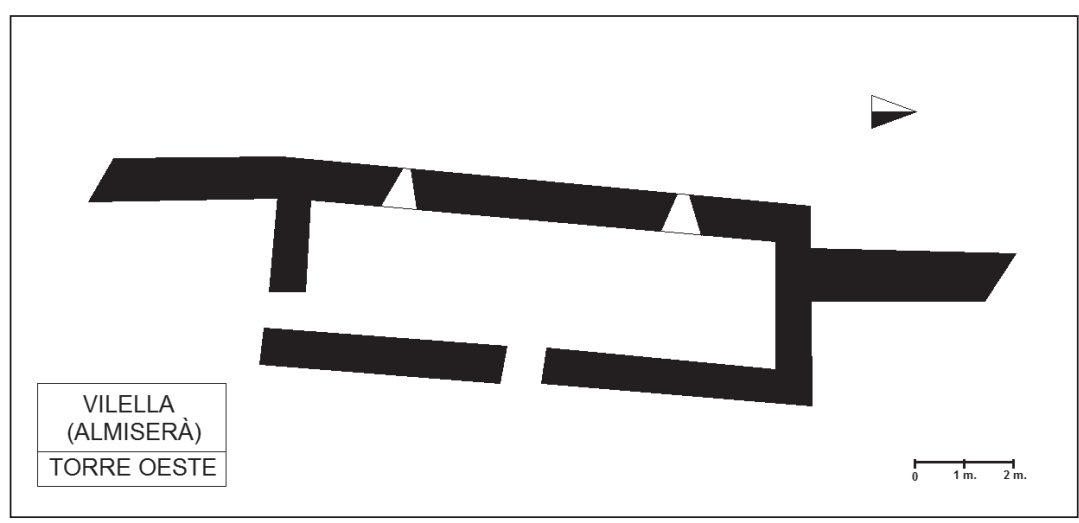

Figura 24: Croquis en planta de la torre oeste 
trata de un hecho nada común, pero la clave se encuentra en la dirección en que corrieron los encofrados durante la construcción, de $\mathrm{O}$ a $\mathrm{E}$ en el lienzo de cerca $\mathrm{N}$ y de $\mathrm{E}$ a $\mathrm{O}$ en el paramento $\mathrm{S}$ del sistema de ingreso; ello indica la existencia de dos equipos trabajando y un cálculo de las medidas poco eficiente. Llegada la construcción, pues, al punto de enjarje, quedaron dos huecos, puesto que el avance de los encofrados había quedado corto, de forma que se optó por rellenarlos con mampostería. Dado que los encofrados del lienzo de cerca debían apoyarse contra las tapiadas de las hiladas tercera y cuarta del paramento O del sistema de ingreso, éstas ya estaban alzadas cuando los constructores del lienzo completaron el paño.

\section{LA TORRE OESTE}

Tras el sistema de ingreso, la torre oeste (figura 25) es la estructura conservada de mayor interés en Vilella: una construcción rectangular de $11 \mathrm{~m}$ de longitud por $4 \mathrm{~m}$ de anchura, dotada de dos vanos de acceso (uno situado en el frente $\mathrm{S}$ y otro en el lateral E) y dos aspilleras que baten la plataforma exterior, situada a varios metros por debajo de la cota de la meseta del refugio.

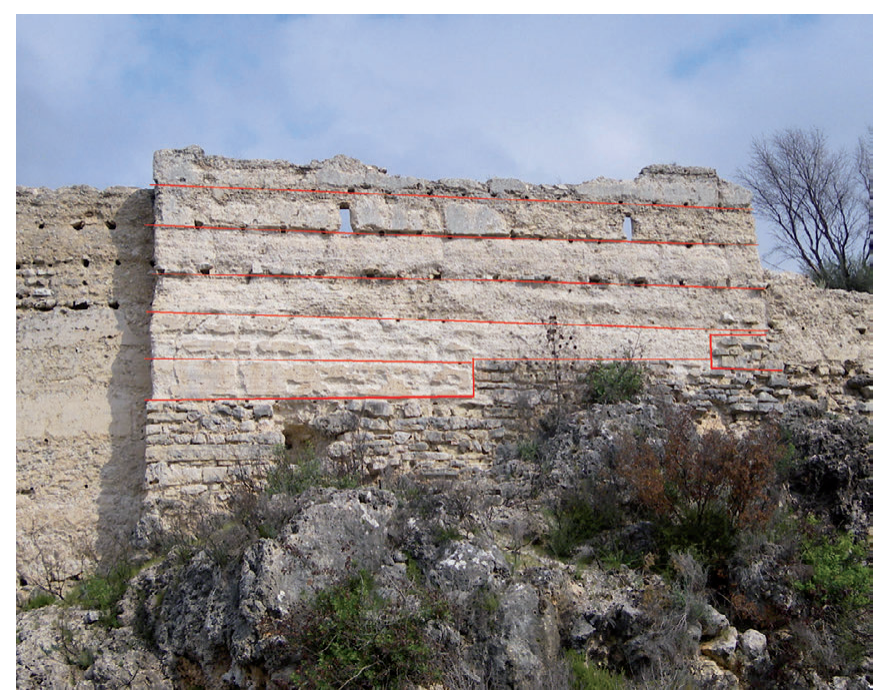

Figura 25: Vista de la torre oeste desde el exterior. Se han marcado las distintas hiladas de tapia; la flecha marca el refuerzo de sillarejos que aparece también en el sistema de ingreso

La torre se encuentra situada al oeste de la peña, sobre una pequeña elevación. Tanto los lienzos NO y SO de la cerca se apoyan contra la torre, la cual aparece como un elemento independiente, de forma que la única traba entre cajas de tapia se da entre los paramentos de la propia estructura. Se trata de una obra coetánea al conjunto del refugio, puesto que los materiales y técnica son homogéneos respecto al resto de muros registrados y estudiados.
Aun así, por su relación con la cerca, puede que se trate de la primera estructura alzada del refugio.

En un primer momento, esta torre fue interpretada por Bazzana y Guichard como un aljibe, a causa de la forma vista en las fotografías aéreas tomadas; recordemos, sin embargo, que Vilella carece de esa estructura de recogida de agua. Tanto los dos vanos como las dos aspilleras, así como la inexistencia de un recubrimiento impermeabilizante en la cara interior de los paramentos, descartan por completo esa interpretación.

La construcción de esta estructura se llevó a cabo con dos tipos de tapia distintos: la mitad inferior de los paramentos N, E y O (visibles solamente desde el exterior debido al desnivel existente entre dentro y afuera) se levantó con tapia hormigonada, mientras que la mitad superior es del tipo de mortero con bloques y áridos; en todos los casos, la anchura de las cajas se ha calculado en $76 \mathrm{~cm}$. Este uso de dos o más tipos de tapia de forma simultánea no resulta en absoluto extraño, pues se logra con ello diferentes resultados estructurales, dado que la tapia hormigonada resiste mucho mejor las cargas y el desgaste que se produce con el tiempo ${ }^{15}$. También se ha comprobado la existencia de una gran variedad de agujales, aunque queremos destacar el registro en la cara externa del paramento $\mathrm{N}$, sobre la tapia hormigonada, de diez agujales rectangulares de pequeño tamaño, con unas medidas de $6 \mathrm{~cm}$ de longitud por $3 \mathrm{~cm}$ de altura como media, así como dos aún menores asociados en pareja horizontal, de 2 × 5'5 cm y de 4 x 4'5 cm; también aparece en este paramento uno de los pocos agujales circulares de Vilella, con un diámetro de $6 \mathrm{~cm}$.

El vano de acceso E, como ocurre con el S, no cuenta con jambas ni dintel, presentando los acabamientos laterales un aspecto liso idéntico al de las caras de las cajas. Muestra una gorronera a cada costado (figura 26), excavada en el frente corto de la tapiada; a diferencia de la $\mathrm{S}$, la gorronera $\mathrm{N}$ cuenta con una roza superior que facilita la inserción y retirada del alamud. Dada la estrecha luz del vano, el cierre debería realizarse con una puerta de madera de una sola hoja. Lo mismo ocurre con el vano $\mathrm{S}$, aunque en este caso no aparecen gorroneras.

En el paramento oeste se han registrado dos aspilleras (figura 27) abiertas cerca de cada una de las esquinas, en la segunda hilada de las tres que quedan en el interior de la torre. Fueron hechas a molde, durante el proceso de

\footnotetext{
Respecto al uso de diferentes tipos de tapia en las torres, no podemos dejar de recomendar el excelente estudio realizado en la torre de alquería de la localidad de Torre de les Maçanes, Alicante (Pérez et al., 2011).
} 


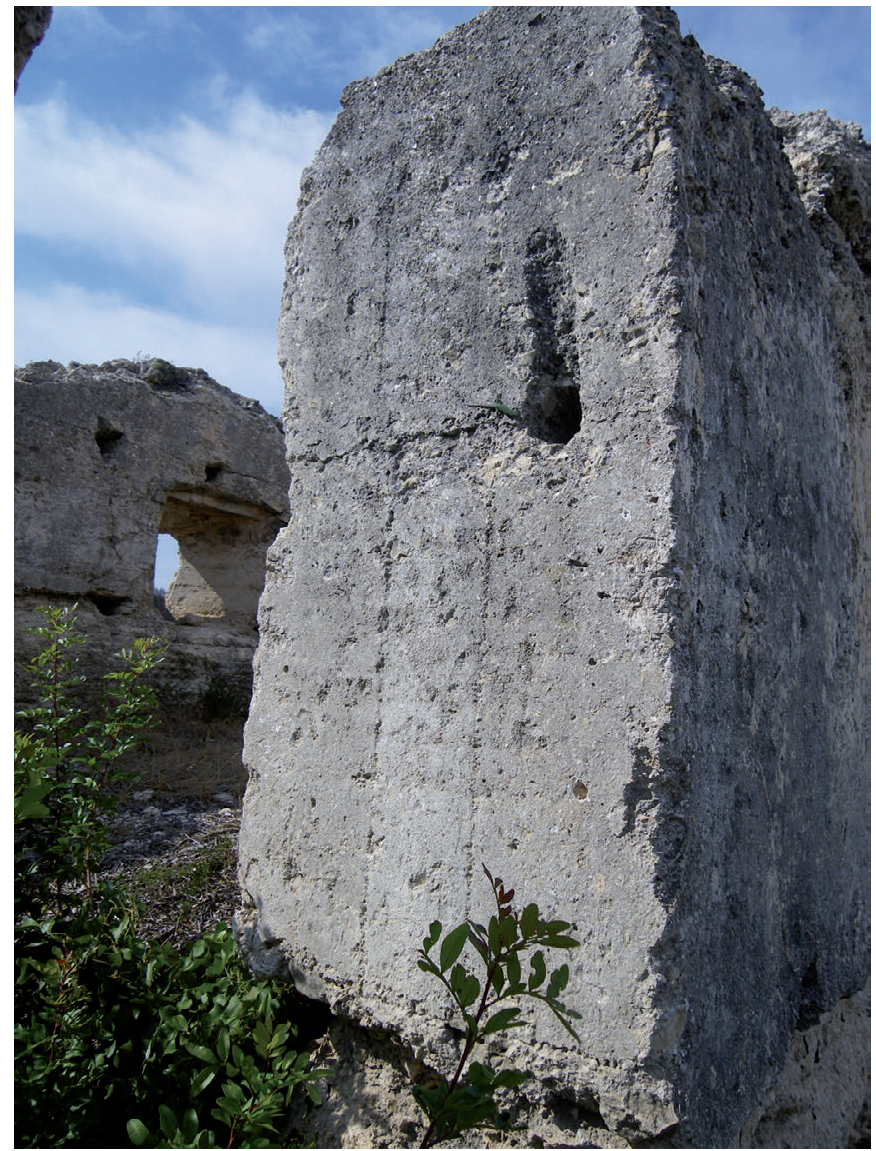

Figura 26: Gorronera del vano E de la torre oeste. Se aprecian las improntas verticales de los cabeceros

encofrado, mediante dos tableros formados por tres tablones horizontales y cubierta de grandes lajas de piedra. La aspillera $\mathrm{S}$ conserva una luz exterior de $18 \mathrm{~cm}$ y una interior de $74 \mathrm{~cm}$, mientras que las medidas de la $\mathrm{N}$ son de $20 \mathrm{~cm}$ en el exterior y de $97 \mathrm{~cm}$ en el interior.

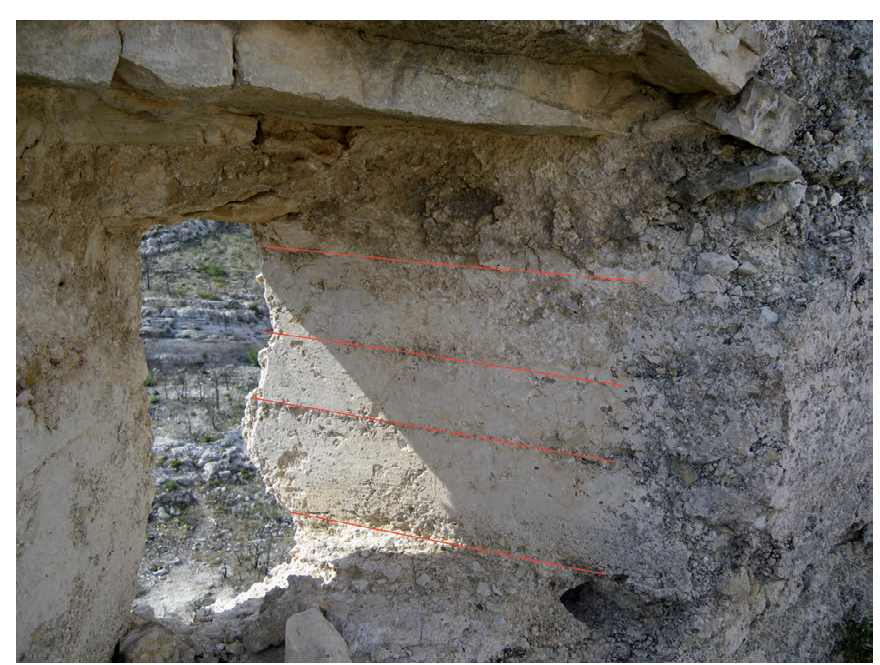

Figura 27: Una de las dos aspilleras de la torre oeste, vista desde el interior de la estructura
Dada la localización de las aspilleras, para batir la plataforma exterior por la que se accede al refugio, esta torre debió cumplir un papel de defensa activa más que de vigilancia. En cuanto a la altura original, resulta imposible determinarla. A pesar de todo, la anchura de los muros no parece permitir la existencia de más de un cuerpo o dos a lo sumo. De todos modos, cualquier hipótesis de restitución resulta arriesgada sin más evidencias.

\section{VALORACIONES FI NALES}

El edificio tradicionalmente conocido como castillo de Vilella o de Almiserat se define como un refugio temporal en altura, alejado de los núcleos de hábitat situados en el entorno inmediato del corredor del río Vernissa, para dificultar su localización en caso de peligro y el acceso hasta él. Como todos los refugios simples andalusíes de ámbito rural, Vilella fue concebido para albergar una determinada cantidad de personas, no excesiva en número, durante un lapso corto de tiempo. Los refugios no presentan, normalmente, defensas complejas más allá de los sistemas de ingreso y los filtros de acceso, y una o dos torres de dimensiones variables; tampoco suelen presentar más estructuras internas que un aljibe, al menos que conozcamos por ahora. Resultaban medidas más que suficientes, puesto que los cristianos no estaban dispuestos a sacrificar tiempo, hombres ni ganancias en largos asedios o complicados asaltos.

A pesar de su deficiente estado de conservación, hemos podido recuperar la función de sus partes y su secuencia de construcción. Vilella se divide en tres sectores: el sistema de ingreso, construido como torreportal con acceso en recodo, la torre oeste y la explanada interior, defendida por varios paños de cerca que desaparecen en la cara S. En cuanto a la secuencia, tanto el sistema de ingreso como la torre oeste fueron construidos de forma independiente aunque simultánea, seguidos de inmediato por los lienzos de cerca para conectar ambas estructuras y cerrar el espacio. Resulta evidente en la torre oeste, donde no existen más relaciones entre cerca y la propia estructura que las de apoyo, mientras que el sistema de ingreso muestra un enjarje con la cerca $\mathrm{N}$ poco planificado o fallido, $\mathrm{y}$ en el que los encofrados de tapial corrieron en dos direcciones distintas hasta encontrarse.

El proceso evolutivo de Vilella se divide en cuatro fases (figura 28): una primera de acondicionamiento del lugar y de construcción de todos los elementos que habían de formar el refugio, situada entre la segunda 
mitad del siglo XII y el primer tercio del siglo XIII; una segunda fase de abandono temporal, encuadrada a grandes rasgos entre los años 1239 y 1247/1258, durante la cual se priva al edificio del necesario mantenimiento; una tercera fase de reocupación entre los años $1247 \mathrm{y}$ 1258 , los de la resistencia musulmana, donde puede que se efectuara el parche o reparación de la cara interior del paramento $\mathrm{O}$ del sistema de ingreso; y una cuarta $\mathrm{y}$ última fase, de abandono, definida por la ruina natural del edificio, que llega hasta la actualidad.

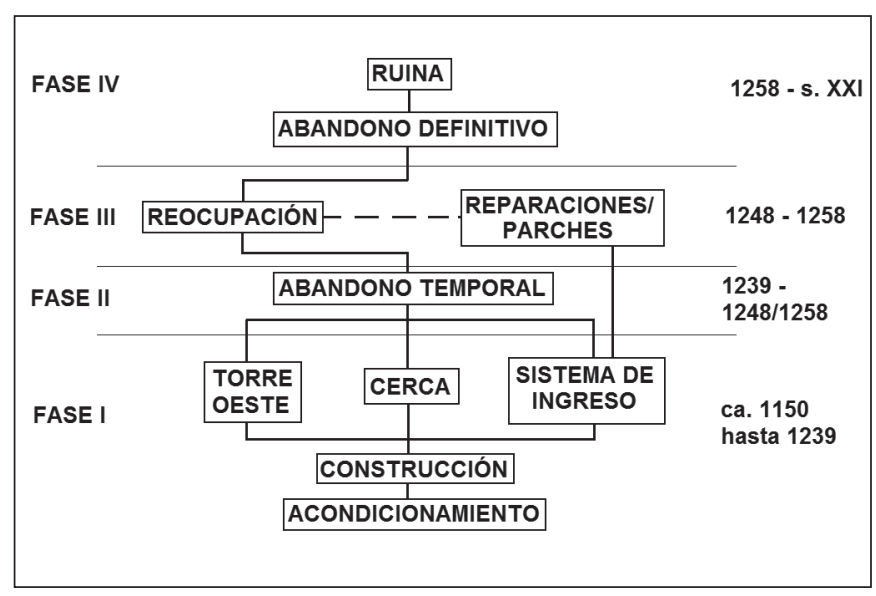

Figura 28: Diagrama cronoevolutivo de las distintas fases del refugio de Vilella

Desgraciadamente, la falta de materiales cerámicos con un contexto fiable y de campañas arqueológicas o de sondeos en el interior del recinto de Vilella, nos impiden precisar cronologías más concretas o determinar otras posibles fases intermedias.

Por lo que respecta a los materiales y técnicas constructivas, se comprueba cómo el uso de distintos tipos de tapias no resulta un hecho arbitrario, sino que responde a la necesidad de hallar ciertos comportamientos estructurales. La tapia hormigonada aparece siempre en los niveles bajos de los edificios, como ocurre en la torre oeste, y es comparativamente la menos común: es una tapia mucho más resistente gracias a su alto contenido en cal y a su fuerte grado de compactación, y ofrece una base sólida que absorbe la presión de las hiladas superiores. Las tapias de mortero con bloques y áridos son mucho más comunes para alzar el resto de paramentos menos comprometidos: la menor cantidad de cal requerida y el uso de bloques del entorno inmediato abaratan su ejecución, por lo que es la más ampliamente utilizada. El tercer tipo, la tapia costrada, requiere algo más de cal para la costra exterior, pero ello no impide que sea también una categoría común y de larga perduración tras la conquista cristiana. Las improntas asociadas a las cajas muestran un uso preferente de encofrados formados por tableros de barzones alternos para facilitar el montaje del cabecero, y de entre 4 y 6 tablones, cifra que no responde a medidas concretas sino a la disponibilidad; la altura es la medida más estable, mientras que la longitud de los encofrados varía entre los 2 y 3 metros. La anchura, por su parte, se halla más relacionada con la altura de los paramentos que con otras posibles causas.

Los agujales muestran una extrema variabilidad: aparecen varios tipos en una misma línea, lo cual denota una falta de patrón o norma en su uso: independientemente de la sección, su cometido es sujetar los costales y los tableros. La aparición de agujales rectangulares de pequeño tamaño, que siempre suelen ir agrupados, podría indicar el uso de tipos de aguja distintos y tal vez duraderos, aunque lo cierto es que la función, sobre todo la de los pares de pequeño tamaño, resulta desconocida. Existe una preferencia sobre los agujales rectangulares de pequeño tamaño en las tapias hormigonadas.

Respecto a la mampostería, esta técnica es muy abundante tanto en Vilella como en los demás edificios defensivos valencianos. No es demasiado común que aparezca para alzar paramentos enteros en época islámica, pero sí resulta muy abundante en zócalos, bases de regularización y cimientos. Las tapiadas nunca se asientan sobre la roca, sino que entre ambos elementos aparecen zócalos mayores o menores de mampostería que pueden llegar a incluir sillarejos en su composición; en los casos en que no hay zócalo, se opta por verter una lechada de mortero de cal sobre la roca y colocar una hilada de mampuestos a modo de pie de aguja. En ningún caso hay contacto directo entre tapias y roca, ni siquiera en la torre oeste donde las tapias hormigonadas podrían haber funcionado, según algunos autores, como cimentación del paramento (Navarro y Jiménez, 2011: 97). Los sillarejos registrados no responden a una planificación, salvo en los dos machones o refuerzos que aparecen en las esquinas exteriores de la torre oeste (paramento $\mathrm{O}$ ) y el sistema de ingreso (paramento $\mathrm{N}$ ).

El refugio de Vilella es un ejemplo de oportunidad y aprovechamiento máximo de los materiales del entorno. Del mismo modo, muestra el impulso propio de las aljamas por protegerse ante el avance de los cristianos. Creemos que el estudio de estos pequeños recintos, aún mal conocidos, puede aportar bastante información acerca de los procesos y técnicas de ejecución con que contaron aquellas comunidades andalusíes. 


\section{BI BLI OGRAFÍ A}

Azuar Ruíz, R. 1981: Castellología medieval alicantina. Área meridional. Instituto de Estudios Alicantinos, Diputación Provincial de Alicante. Alicante.

Azuar Ruíz, R. 1989: Denia islámica. Arqueología y poblamiento. Instituto de Cultura Juan Gil-Albert. Alicante.

Azuar Ruíz, R. 1995: "Las técnicas constructivas en al-Andalus. El origen de la sillería y del hormigón de tapial”, en Iglesia Duarte, J. I. de la. (coord.), $V$ Semana de Estudios Medievales: Nájera, pp. 125-142. Nájera.

Bazzana, A. y Guichard, P. 1980: "Note sur la localisation du château de Vilella", Mélanges de la Casa de Velázquez, 16, pp. 437-442.

Bazzana, A. 1983a: "El món islàmic", en Novell N. y Muñoz, J. (dir.), El llibre de la Safor, pp. 249-256. Sueca.

Bazzana, A. 1983b: «La défense des communautés rurales dans l'Espagne musulmane», en Bazzana, A. y Humbert A. (eds.), Prospections aériennes. Les paysages et leur histoire. Série Recherches en Sciences Sociales, fasc. VII, pp. 105-122. Casa de Velázquez. Madrid.

Bazzana, A. y Guichard, P. 1983: «Habitats et sites défensifs d'époque médiéval: éléments d'un recherche dans la région valencienne», Estudis Castellonencs, 1, pp. 611-696.

Bazzana, A., Guichard, P. y Créssier, P. 1988: Les châteaux ruraux d'alAndalus. Histoire et archéologie des husun du sud-est de l'Espagne. Publications de la Casa de Velázquez, série Archéologie, XI. Madrid.

Bazzana, A.: 2002: "Morfología y papel de los castillos musulmanes (siglos X-XIII): La Ribera y otros ejemplos", en Furió Diego, A. y Aparici, J. (coords.), Castells, torres y fortificacions en la Ribera del Xúquer. VIII Assemblea d'Història de la Ribera, pp. 19-50. Cullera.

Camarena, J. 1965: Historia del distrito de Gandía. Instituto Duque Real Alonso el Viejo. Gandía.

Centre d'Estudis Contestans (coor.) 1996: El Comtat: una terra de castells. Cocentaina.

Centre d'Estudis Contestants (coor.) 2009: Els Musulmans al Comtat. 1609-2009: 400 anys d'expulsió, catálogo de la Exposición (2009-2010). Cocentaina.

Epalza, M. de 1984: "Funciones ganaderas de los albacares en las fortalezas musulmanas", Sharq al-Andalus. Estudios árabes, 1, pp. 47-54.

Ferrando i Francés, A. (ed.) 1984: Llibre del Repartiment. Ed. Vicent Garcia. València.

Font, F. e Hidalgo, P. 1991: El tapial, una tècnica constructiva mil·lenària. Castellón ( $2^{\mathrm{a}}$ ed.).

Graciani García, A. 2008a: «La técnica del tapial en Andalucía Occidental», en Construir en Al Andalus. Actas de las III Jornadas Técnicas de la Alcazaba de Almería (2007), pp. 111-140. Patronato de la Alcazaba de Almería. Almería.

Graciani García, A. 2008b: «Técnicas de intervención en fábricas históricas de tapial», en Actas de las II Jornadas de Investigación en Construcción, pp. 85-99. Madrid.

Graciani García, A. 2009: «Improntas y oquedades en fábricas históricas de tapial. Indicios constructivos», en Actas del VI Congreso Nacional de Historia de la Construcción, vol. 2, pp. 683-692. Instituto Juan de Herrera, Madrid.

Graciani García, A. y Tabales Rodríguez, M. 2003: «Typological observations on tapia walls in the area of Sevilla. 11th - 19th centuries», en Proceedings of the First International Congress on Construction History, vol. II, pp. 1093-1106. Instituto Juan de Herrera, Escuela Técnica Superior de Arquitectura de Madrid, Madrid.
Graciani García, A. y Tabales Rodríguez, M. 2008: "El tapial en el área sevillana. Avance cronotipológico estructural”, Arqueología de la Arquitectura, 5 , pp. 135-158.

Guichard, P. 1982: "Los castillos musulmanes del norte de la provincia de Alicante", Anales de la Universidad de Alicante. Historia Medieval, 1, pp. $29-46$.

Guichard, P. 2001: Al-Andalus frente a la conquista cristiana: los musulmanes de Valencia (siglos XI-XV). Biblioteca Nueva, Universitat de València, València.

López Elum, P. 2002: Los castillos valencianos en la Edad Media (materiales y técnicas constructivas), 2 vols. Biblioteca Valenciana. Generalitat Valenciana, Conselleria de Cultura i Educació, València.

Márquez Bueno, S. y Gurriarán Daza, P. 2008: "Recursos formales y constructivos en la arquitectura militar almohade de al-Andalus", Arqueología de la Arquitectura, 5, pp. 115-134.

Martín Civantos, J. 2008: "Ensayo de sistematización de las técnicas constructivas andalusíes de la provincia de Granada", en Sabaté, F. (dir.), Arqueología medieval. La transformación de la frontera medieval musulmana, vol. II; pp. 119-151. Àgira col·lecció, Lérida.

Navarro Palazón, J. y Jiménez Castillo, P. 2011: "Materiales y técnicas constructivas en la Murcia andalusí (siglos X-XIII)", Arqueología de la Arquitectura, 8, pp. 85-120.

Pérez Jiménez, R. 2009: Restauració de la Torre d'Almudaina. MARQ, Diputación de Alicante y Ayuntamiento de Almudaina, Alicante.

Pérez Jiménez, R., Ortuño Terres, E. 2011: Musealización de la Torre de Maçanes. Diputación de Alicante y Ayuntamiento de la Torre de les Maçanes, Alicante.

S/a. 1996: Bairén i els castells de la Safor. Casa d'Oficis del Castell de Bairén, Gandía.

Sánchez i Signes, M. 2010: El recinte oriental del castell de Bairén (Gandia). Recerques del Museu d'Alcoi, 19, pp. 137-156.

Segura Beltrán, F. y Carmona González, P. 1999: Las inundaciones en la plana de Gandía: formas y procesos, Cuadernos de Geografía, 65-66, pp. 45-60.

Tabales Rodríguez, M. 1999: «Algunas notas sobre fábricas murarias almohades de Sevilla», en Los almohades. Su patrimonio arquitectónico y arqueológico en el sur de al-Andalus, pp. 75-90. Sevilla.

Tabales Rodríguez, M. 2000: «Algunas reflexiones sobre fábricas y cimentaciones sevillanas en el periodo islámico», en Actas del III Congreso Nacional de Historia de la Construcción, vol. II, pp. 1077-1089. Instituto Juan de Herrera, CEHOPU y Universidad de Sevilla, Madrid.

Torró i Abad, J. e Ivars, J. 1990: «La vivienda rural mudéjar y morisca en el sur del País Valenciano», en La casa hispano-musulmana: aportaciones de la arqueología, pp. 73-81. Patronato de la Alhambra y Generalife, Casa de Velázquez y Museo de Mallorca, Granada.

Torró i Abad, J. y Segura, J. M. ${ }^{a}$ 1991: «Asentamientos cristianos fortificados (siglos XIII-XIV): una aproximación tipológica para el sur del País Valenciano», en Azuar, R. (comp.), Fortificaciones y castillos de Alicante, pp. 147-181. Alicante.

Torró i Abad, J. 1998: «Fortificaciones en Yibal Balansiya. Una propuesta de secuencia», en Castillos y territorio en al-Andalus, pp. 385-418. Granada.

Torró i Abad, J. 2006: El naixement d'una colònia. Dominació i resistència a la frontera valenciana (1238-1276). Publicacions de la Universitat de Valencia, Valencia. 